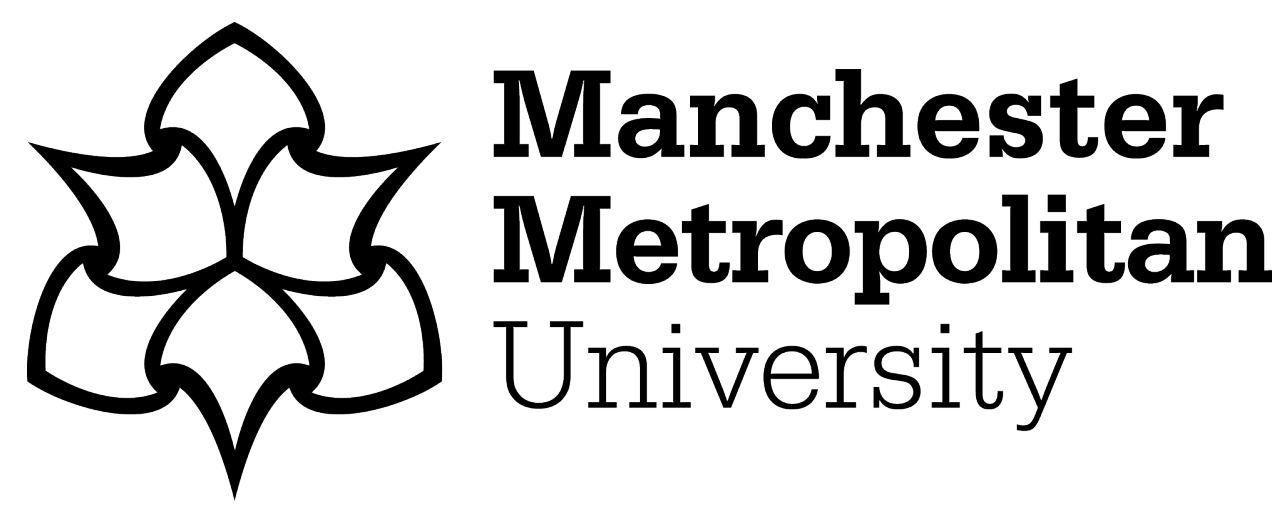

Mitchell, Jane A, Kirkby, Nicholas S, Ahmetaj-Shala, Blerina, Armstrong, Paul C, Crescente, Marilena ORCID logoORCID: https://orcid.org/00000003-3164-512X, Ferreira, Plinio, Lopes Pires, Maria Elisa, Vaja, Ricky and Warner, Timothy D (2021) Cyclooxygenases and the cardiovascular system. Pharmacology and Therapeutics, 217. p. 107624. ISSN 0163-7258

Downloaded from: https://e-space.mmu.ac.uk/628016/

Version: Accepted Version

Publisher: Elsevier

DOI: https://doi.org/10.1016/j.pharmthera.2020.107624

Usage rights: Creative Commons: Attribution-Noncommercial-No Derivative Works 4.0

Please cite the published version 


\section{Cyclooxygenases and the Cardiovascular System}

Jane A. Mitchell ${ }^{1}$, Nicholas S. Kirkby ${ }^{1}$, Blerina Ahmetaj-Shala ${ }^{1}$, Paul Armstrong ${ }^{2}$, Marilena Crescente ${ }^{2}$, Plinio Ferreira ${ }^{1}$, Maria Elisa Lopes Pires ${ }^{1}$, Ricky K. Vaja ${ }^{1}$ and Timothy D. Warner ${ }^{2}$.

${ }^{1}$ Cardiothoracic Pharmacology, National Heart and Lung Institute, Imperial College London, SW7 2AZ, United Kingdom. ${ }^{2}$ Blizard Institute, Barts and The London School of Medicine and Dentistry, The Blizard Building, 4 Newark Street, London E1 2AT, United Kingdom.

JAM and NSK contributed equally and share first author:

$\mathrm{PA}, \mathrm{MC}, \mathrm{PF}, \mathrm{MP}$ and RV contributed equally and their names appear in alphabetical order.

\section{Correspondence to:}

Jane A. Mitchell or Nicholas S. Kirkby

j.a.mitchell@ic.ac.uk and n.kirkby@imperial.ac.uk

Cardiothoracic Pharmacology,

National Heart and Lung Institute,

Imperial College London,

Sir Alexandra Fleming Building,

Imperial College Rd,

Kensington,

London SW7 2AZ

United Kingdom 


\section{Abstract}

Cyclooxygenase (COX)-1 and COX-2 are centrally important enzymes within the cardiovascular system with a range of diverse, sometimes opposing, functions. Through the production of thromboxane, COX in platelets is a pro-thrombotic enzyme. By contrast, through the production of prostacyclin, COX in endothelial cells is antithrombotic and in the kidney regulates renal function and blood pressure. Drug inhibition of COX within the cardiovascular system is important for both therapeutic intervention with low dose aspirin and for the manifestation of side effects caused by nonsteroidal anti-inflammatory drugs. This review focuses on the role that COX enzymes and drugs that act on COX pathways have within the cardiovascular system and provides an in-depth resource covering COX biology and pharmacology. The review goes on to consider the role of coX in both discrete cardiovascular locations and in associated organs that contribute to cardiovascular health. We discuss the importance of, and strategies to manipulate, the thromboxane: prostacyclin balance. Finally within this review the authors discuss testable COX-2-hypotheses intended to stimulate debate and facilitate future research and therapeutic opportunities within the field.

\section{Key Words}

Aspirin, fish oil, ibuprofen, celecoxib, cyclooxygenase, heart attack 


\section{Abbreviations}

Formatted: Italian

Apolipoprotein A-I (apoAI)

Asymmetric dimethylarginine (ADMA)

Cyclooxygenase (COX)

Docosahexanoic acid (DHA)

Eicosapentaenoic acid (EPA)

Endothelial nitric oxide synthase (eNOS)

High density lipoprotein (HDL)

Microsomal PGE synthase (mPGES)

Nitric oxide (NO)

Nonsteroidal anti-inflammatory drugs (NSAIDs)

Peroxisome proliferator-activated receptor (PPAR)

Prostacyclin $\left(\mathrm{PGI}_{2}\right)$

Prostacyclin, I-prostanoid receptor (IP)

Prostacyclin synthase (PGIS)

Prostaglandin (PG)

Thromboxane ( $\mathrm{TXA}_{2}$ )

Thromboxane synthase (TXAS)

Thromboxane, T-prostanoid receptor (TP) 


\section{Table of Contents}

1. Introduction

2. Cyclooxygenase expression and activity within the cardiovascular system

3. The prostacyclin thromboxane balance

3.1. Reducing thromboxane:

3.2. Boosting $\mathrm{PGI}_{2}$ :

3.2.1. Synthesis

3.2.2. Half-life

3.2.3. $P \mathrm{PGI}_{2}$ drugs

3.2.4. 2-series versus 3-series prostanoids: the arachidonic acid-EPA balance

4. Effects of NSAIDs in the cardiovascular system

5. Mechanisms by which cyclooxygenase protects the cardiovascular system

5.1. $\operatorname{cox}-1$

5.2. $\quad \operatorname{coX}-2$

5.2.1. Kidney

5.2.2. Endothelium

5.2.3. Gut

5.2.4. Thymus

5.2.5. Brain

7. Funding

8. Conflict of Interest statement

9. References 


\section{Introduction}

Cyclooxygenase (COX), also known as prostaglandin (PG)H synthase, is the first enzyme in the conversion of fatty acid substrates, most notably arachidonic acid, to $\mathrm{PGH}_{2}$. $\mathrm{PGH}_{2}$ is then further metabolized by downstream synthase enzymes to a range of prostanoids. COX can also use other fatty acid substrates including eicosapentaenoic acid (EPA) and dihomo- $\psi$-linolenic acid resulting in $\mathrm{PGH}_{3}$ and $\mathrm{PGH}_{1}$, and associated prostanoid products, respectively; in prostanoid nomenclature, the subscript number ( 1 to 3 ) denotes the total number of double bonds in the alkyl substituents. The rate-limiting step in prostanoid formation from COX is availability of substrate. In resting cells arachidonic acid is highly restricted to plasma phospholipids and generally only released when cells are stimulated following activation of calcium dependent isoforms of phospholipase $A_{2}$ (Flower \& Blackwell, 1976; Kirkby, et al., 2015; Mitchell \& Kirkby, 2019; Mitchell, et al., 2018). In some systems arachidonic acid can also be liberated from phosphatidylinositol by the phospholipase $C$ pathway (de Nucci, Gryglewski, Warner, \& Vane, 1988).

COX is present in two isoforms, COX-1 and COX-2, derived from different genes and sharing $\approx 60 \%$ homology at the protein level (Kang, Mbonye, DeLong, Wada, \& Smith, 2007). A third isoform (COX$3)$, which is a spliced variant of COX-1 (Chandrasekharan, et al., 2002), has been described but because this variant retains intron-1, translation results in a frame shift producing a protein devoid of 'COX' activity in rats (Snipes, Kis, Shelness, Hewett, \& Busija, 2005) and mice (Kis, et al., 2006) and with no predicted enzymatic activity in humans (Kis, Snipes, \& Busija, 2005). For all intents and purposes, therefore, there are just two functional COX enzymes, COX-1 and COX-2.

COX-1 has the traditional features of a house keeping gene (Azizkhan, Jensen, Pierce, \& Wade, 1993) in that it lacks a canonical TATA or CAAT box and is GC-rich (Kang, et al., 2007). As such COX-1 is constitutively expressed in most cells to some degree and highly expressed in some tissues, including platelets and blood vessels. Whilst COX-1 is constitutively expressed its levels can be up regulated in endothelial cells by growth factors (Bryant, Appleton, \& Mitchell, 1998) and physiological stimuli such as shear stress (Okahara, Sun, \& Kambayashi, 1998).

COX-2 on the other hand has the characteristics of an immediate early response gene with multiple cis-elements in the 5'-flanking region that regulate gene expression via transcription factors such as NFAT, CREB and NFKB (Kang, et al., 2007). As a result, COX-2 is rapidly induced at sites of inflammation 
(Vane, et al., 1994) and in cancer (Hashemi Goradel, Najafi, Salehi, Farhood, \& Mortezaee, 2019). Importantly, COX-2 is also constitutively expressed in the absence of inflammation (Mitchell \& Kirkby, 2019) in select regions such the brain, gut, thymus, lung and the inner medulla region of the kidney (Harris, et al., 1994; Kirkby, et al., 2016; Kirkby, et al., 2013; Mitchell, et al., 2018; Zidar, et al., 2009).

Prostanoids are a group of highly potent lipid mediators with diverse effects, dictated by the presence of affiliated prostanoid receptors. Prostanoid receptors are classical G-protein-coupled receptors utilizing either cAMP or phosphatidylinositol signaling pathways (Alexander, et al., 2019) to regulate homeostasis and inflammation across all organ systems within the body.

The COX pathway has been exploited therapeutically, although without doubt the full potential of COX and prostanoids in the treatment of human disease remains to be realised. In this regard, drug formulations of prostanoids derived from the COX pathway including prostacyclin $\left(\mathrm{PGI}_{2}\right), \mathrm{PGE}_{2}, \mathrm{PGE}_{1}$ and $\mathrm{PGF}_{2 \alpha}$ are used in a range of indications. For example, drug formulations of $\mathrm{PGI}_{2}$ (and related molecules) are used to treat pulmonary arterial hypertension and peripheral vascular disease. PGE 2 and $\mathrm{PGE}_{1}$ are used in labor, in babies with heart defects to control closing of the patent ductus arteriosus and as combination therapies with NSAIDs to prevent gastric ulcers, while synthetic forms of $\mathrm{PGF}_{2 \alpha}$ are used to reduce intraocular pressure in the treatment of glaucoma. However, on a global and population level, the most important drug opportunity presented by the COX pathway is in compounds that block enzyme activity and subsequent prostanoid production. Nonsteroidal antiinflammatory drugs (NSAIDs), which include celecoxib, ibuprofen and naproxen, used in the treatment of pain and fever and aspirin (in low dose) used for the secondary prevention of heart attacks and strokes, all work by blocking COX. They represent some of the world's most widely used prescription and over the counter medications. Shortly after COX-2 was discovered, early pharmacological studies identified key differences in the potency of NSAIDs between COX-1 and COX2 (Meade, Smith, \& DeWitt, 1993; Mitchell, Akarasereenont, Thiemermann, Flower, \& Vane, 1993; Warner, et al., 1999), these were later explained by structural differences in the active sites of the enzymes (Garavito, Malkowski, \& DeWitt, 2002; Y. S. Khan, Gutierrez-de-Teran, \& Aqvist, 2018). Since COX-2 is the therapeutic target of NSAIDs, selective COX-2 inhibitors were introduced to the market in the early 2000s to avoid the notorious gastrointestinal effects associated with traditional older style medications, which block both isoforms. COX-2 selective NSAIDs are comparable with traditional non-selective drugs for treating pain and inflammation with reduced gastrointestinal side 
effects (Coxib, et al., 2013). However, now the major concern across all forms of NSAID therapy are the cardiovascular side effects associated with these drugs, which were only realised in the post 2000s era.

This review focuses on the role that COX enzymes and drugs that act on COX pathways have within the cardiovascular system. Drug inhibition of COX within the cardiovascular system is important for both therapeutic intervention and for the manifestation of side effects. This review considers the role of COX in both discrete cardiovascular locations and in associated organs that contribute to cardiovascular health. Finally within this review the authors discuss testable COX-2 hypotheses intended to stimulate debate and facilitate future research and therapeutic opportunities within the field.

\section{Cyclooxygenase expression and activity within the cardiovascular system}

As discussed above, COX-1 is a typical house-keeping gene that is expressed throughout the cardiovascular system with particularly high abundance in blood vessels and platelets. Within healthy blood vessels COX-1 is mainly located within the endothelial layer where it couples with prostacyclin synthase (PGIS) to produce mainly $\mathrm{PGI}_{2}$. In platelets COX couples with thromboxane (TXA $)_{2}$ synthase to produce mainly $\mathrm{TXA}_{2}$. While COX-2 is expressed in areas of vascular inflammation and disease it is only sparsely expressed in the majority of blood vessels and essentially absent in platelets. Studies from knockout mice confirm that COX-1 is the predominate driver of 'gross' $\mathrm{PGI}_{2}$ production. However, as discussed below, constitutive endothelial COX-2 does have cardio-protective effects, although the anatomical locations and mechanistic paradigm of endothelial COX-2 remain to be determined.

\section{The prostacyclin thromboxane balance}

$\mathrm{PGI}_{2}$ inhibits platelet activation and is thereby an anti-thrombotic mediator. $\mathrm{PGI}_{2}$ also inhibits lipid accumulation (Hajjar, et al., 1982) and vascular smooth muscle cell remodeling in humans in vivo (Sinzinger, et al., 1987) and in isolated vascular smooth muscle cells in vitro (Akopov, et al., 1988). In direct contrast, $\mathrm{TXA}_{2}$ stimulates platelet activation (Crescente, Menke, Chan, Armstrong, \& Warner, 2019), increases cholesterol accumulation (Baldenkov, Akopov, Ryong, \& Orekhov, 1988) and vascular smooth muscle cell proliferation (Akopov, et al., 1988). In this way, levels of $\mathrm{PGI}_{2}$ and $\mathrm{TXA}_{2}$ operate within a tight margin of pro- and anti-thrombotic tone to keep blood flowing under 
physiological conditions and allowing rapid platelet aggregation when needed for haemostasis (Knowles \& Warner, 2019). Within limits, therefore, a healthy, protected cardiovascular system is one where $\mathrm{PGI}_{2}$ activity 'outweighs' TXA $A_{2}$ activity. Therapeutically the $\mathrm{PGI}_{2}: \mathrm{TXA}_{2}$ balance can be manipulated towards an antithrombotic tone by (i) reducing $\mathrm{TXA}_{2}$, (ii) boosting $\mathrm{PGI}_{2}$ or (iii) reducing 2-series and increasing 3-series prostanoids with omega-3 fatty acids as summarised in Figure 1.

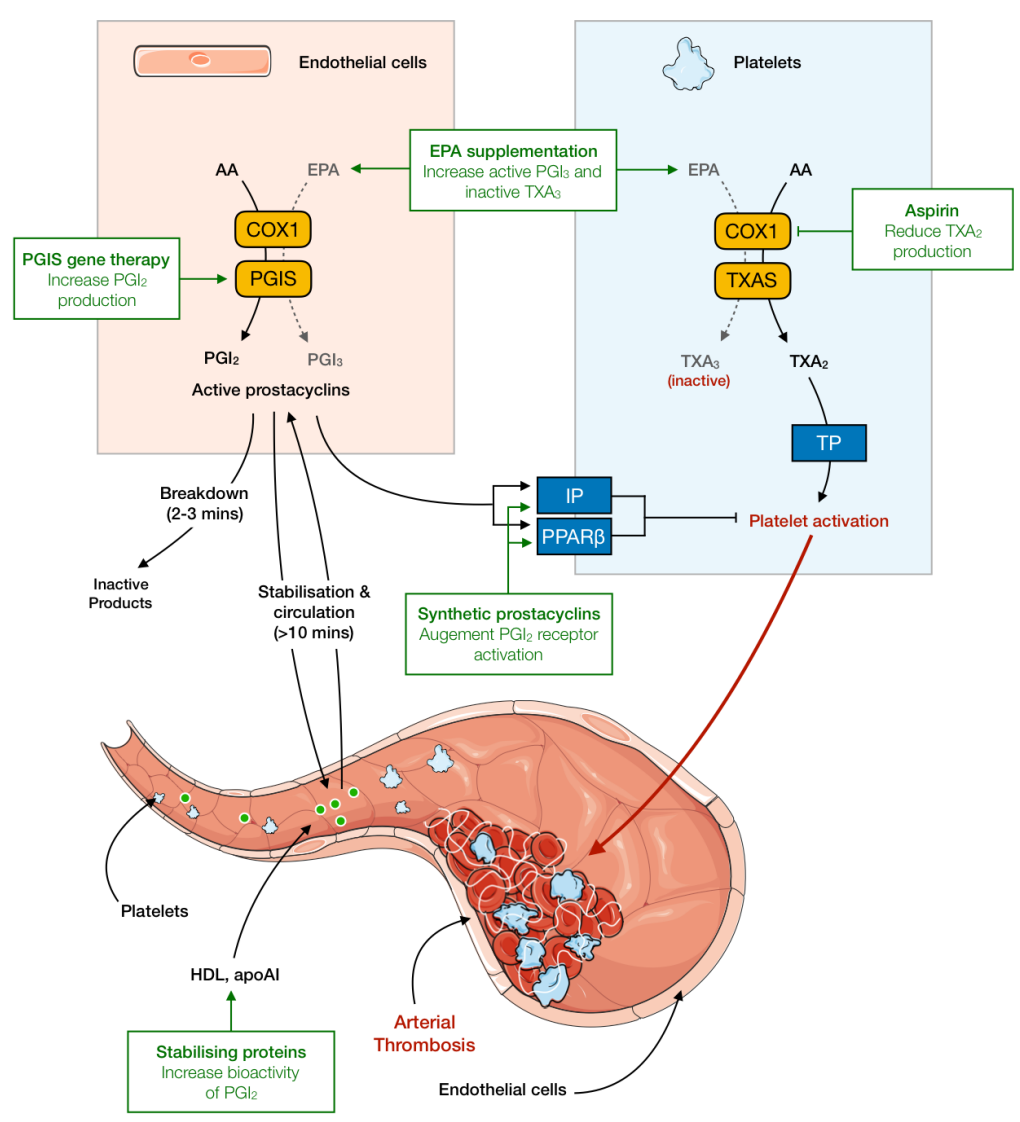

Figure 1: The prostacyclin thromboxane balance and strategies for therapeutic manipulation. $A A$, arachidonic acid; EPA, eicosapentaenoic acid; COX, cyclooxygenase; PGIS, prostacyclin synthase; TXAS, thromboxane synthase; IP, I-prostanoid receptor; TP, T-prostanoid receptor; PPAR, peroxisome proliferator-activated receptor; HDL, high density lipoprotein; apoAl, apolipoprotein A-I.

3.1. Reducing thromboxane 
Inhibiting platelet COX-1 with low dose aspirin (70-120mg daily) can selectively reduce TXA 2 and as aspirin is cheap and effective, this approach is used worldwide for secondary protection against arteriothrombotic events. The selectivity of aspirin against platelet COX-1 and consequently TXA production is explained by its unique pharmacology, which separates it from other NSAIDs. Firstly, it is the only drug in the class that works irreversibly, and secondly it has a short half-life in the body. The irreversible mechanism of action of aspirin means that after tissues are exposed to it prostanoid production can only resume through the synthesis of new enzyme. As platelets have no nucleus they cannot generate new protein and remain inhibited for their lifetime. Conversely, because aspirin rapidly disappears from the circulation, its effects can be overcome between doses by regeneration of the enzyme in nucleated cells such as vascular endothelial cells and so the production of other prostanoids, notably $\mathrm{PGI}_{2}$, can be largely maintained (Heavey, Barrow, Hickling, \& Ritter, 1985). Additional selectivity arises through the exposure of circulating platelets to higher levels of aspirin in the portal circulation, prior to first-pass hepatic metabolism, than in the systemic circulation meaning that the majority of the endothelium is somewhat protected from its effects. Together these processes mean that the cumulative effects of low dose aspirin therapy are to reduce platelet TXA 2 production by more than $95 \%$ while endothelial $\mathrm{PGI}_{2}$ production is partially preserved. The pharmacology of TXA 2 and mechanistic explanations of how aspirin works in platelets is reviewed in detail by Crescente and colleagues (Crescente, et al., 2019).

\subsection{Boosting $\mathrm{PGI}_{2}$}

Boosting $\mathrm{PGI}_{2}$ at the effector site can be achieved in three functional ways; (i) increasing synthesis/release, (ii) stabilizing $\mathrm{PGI}_{2}$ and increasing its half-life and (iii) supplementing endogenous $\mathrm{PGI}_{2}$ with $\mathrm{PGI}_{2}$-drugs.

\subsubsection{Synthesis}

$\mathrm{PGI}_{2}$ release is regulated by the concerted actions of COX and PGIS. Reduced PGIS expression is seen in the lungs of patients with pulmonary arterial hypertension (Tuder, et al., 1999) and in the resistance arteries of patients with type 2 diabetes (Safiah Mokhtar, et al., 2013) whilst mutations in PGIS are linked to hypertension (Nakayama, et al., 2002), cerebral infarction (Nakayama, et al., 2000) and myocardial infarction (Nakayama, 2010). In line with this, increasing PGIS expression through gene therapy is an emerging therapeutic possibility, currently at the preclinical stage, with target indications including peripheral vascular disease (Shimamura, Nakagami, Taniyama, \& Morishita, 
2014), vein grafts (Newby \& Baker, 1999), pulmonary hypertension (Nagaya, et al., 2000) and stroke (Lin, et al., 2002).

An additional way in which $\mathrm{PGl}_{2}$ release can be increased is by selectively blocking $\mathrm{PGE}_{2}$ synthesis through the use of microsomal PGE synthase (mPGES)-1 inhibitors. PGE 2 synthesis occurs by the concerted actions of COX and PGES or (under some conditions) non-enzymatically. There are 3 isoforms of PGES, mPGES-1, mPGES-2 and cytosolic PGES. mPGES-1 is often co-expressed with COX2 and is an established therapeutic target for inhibitor drugs to treat inflammation and pain (Bergqvist, Morgenstern, \& Jakobsson, 2019). Work from our group and others show that loss of mPGES-1 increases plasma $\mathrm{PGI}_{2}$ in mice in vivo (Kirkby, et al., 2019) or tissue $\mathrm{PGI}_{2}$ in human vessels (Ozen, et al., 2017). These observations are in line with reports showing that loss of mPGES-1 in mice can be cardio-protective since it slows atherosclerosis (Wang, et al., 2006), inhibits aortic aneurysm in hyperlipidemic mice (M. Wang, et al., 2008), and smooth muscle remodeling following vascular injury (Wang, et al., 2011). The relative contributions of increased $\mathrm{PGI}_{2}$ versus reduced $\mathrm{PGE}_{2}$ in the cardio protective effects of blocking of mPGES-1 remain to be established.

\subsubsection{Half-life}

$\mathrm{PGI}_{2}$ is unstable in aqueous solution at physiologic $\mathrm{pH}$ and temperature. This has given rise to the idea that $\mathrm{PGI}_{2}$ is a locally acting anti-thrombotic hormone (Christ-Hazelhof \& Nugteren, 1981). However, $\mathrm{PGI}_{2}$ is stabilized by binding to serum proteins such that in blood or plasma $\mathrm{PGI}_{2}$ has a halflife estimated to be between 3 to 15 minutes (Dusting, Moncada, \& Vane, 1978; Pifer, Cagen, \& Chesney, 1981) which, if applicable in vivo would suggest that $\mathrm{PGI}_{2}$ circulates (Moncada, Korbut, Bunting, \& Vane, 1978). The ability of plasma to stabilize $\mathrm{PGI}_{2}$ is reduced in patients with cardiovascular disease including thrombotic thrombocytopenic purpura (Wu, Hall, Rossi, \& Papp, 1985), stroke (Stein, Papp, Weiner, \& Wu, 1985), myocardial infarction (Sinzinger, Fitscha, \& Tiso, 1990) and unstable angina (Aoyama, Yui, Morishita, \& Kawai, 1990). In addition to albumin, components of $\mathrm{HDL}$, including apolipoprotein A-I have been identified as 'stabilizing factors' for $\mathrm{PGI}_{2}$ (Yui, et al., 1988) leading to the idea that reduced HDL levels may contribute to cardiovascular risk due to reduced circulating levels of biologically active $\mathrm{PGI}_{2}$ (Pirich, Efthimiou, O'Grady, \& Sinzinger, 1997). Whilst the therapeutic utility of drugs designed to stabilize endogenous $\mathrm{PGI}_{2}$ remains to be determined, such drugs may be an attractive option particularly for those patients where changes in plasma constituents result in a reduced ability to stabilize $\mathrm{PGI}_{2}$. 


\subsection{3. $\mathrm{PGI}_{2}$ drugs}

In addition to boosting endogenous $\mathrm{PGI}_{2}$, the $\mathrm{PGI}_{2}: \mathrm{TXA}_{2}$ balance can be manipulated by supplying $\mathrm{PGI}_{2}$ as a drug. $\mathrm{PGI}_{2}$ drugs are based on synthetic agonists of $\mathrm{PGI}_{2}$ receptor pathways. Much of the functional effects of $\mathrm{PGI}_{2}$ are mediated through activation of the cell surface prostacyclin (IP) receptor linked to activation of adenylate cyclase and increases in the second messenger CAMP. IP receptor pharmacology and signal transduction is reviewed in detail by Midgett and colleges (Midgett, Stitham, Martin, \& Hwa, 2011). It should also be noted that when produced in excess of IP receptor capacity, $\mathrm{PGI}_{2}$ may also crosses over to other prostanoid receptors leading to vasoconstriction in some vessels (Luo, Liu, \& Zhou, 2016).

$\mathrm{PGI}_{2}$ can also activate the cytosolic nuclear receptor PPAR $\beta$. PPAR $\beta$ signalling includes the classical PPAR-RXR pathway to regulate target gene induction and trans-repression of the transcription factor BCL-6 (Lee, et al., 2003) and/or protein kinase PKC $\alpha$ (Ali, Armstrong, et al., 2009; Ali, Hall, Desvergne, Warner, \& Mitchell, 2009; Mitchell, et al., 2014). The pharmacological relationship between $\mathrm{PGI}_{2}$ drugs in their interaction with IP versus PPARs is reviewed elsewhere (Belvisi \& Mitchell, 2009; Bishop-Bailey, 2015; Mitchell, et al., 2014; Mitchell \& Kirkby, 2019). $\mathrm{PGI}_{2}$ drugs include, injectable treprostinil, iloprost, beraprost and newer orally active selexipag (Mitchell, et al., 2014). They are perhaps surprisingly not used as anti-thrombotic medications but rather for the treatment of particular vascular diseases as mentioned above (Mitchell, et al., 2014). This is primarily because $\mathrm{PGI}_{2}$ drugs are restricted by their side effects, which means their use is limited to conditions with finite therapeutic options.

\subsubsection{2-series versus 3 -series prostanoids: the arachidonic acid-EPA balance}

Finally, the $\mathrm{PGI}_{2}: \mathrm{TXA}_{2}$ balance can be indirectly manipulated by changing the ratio of COX substrate from omega- 6 arachidonic acid to omega-3 EPA and docosahexanoic acid (DHA), resulting in the reduction of 2-series and increase of 3-series prostanoids. Arachidonic acid derived from meat, poultry, nuts and seeds, is a principle component of cell membranes (Tallima \& El Ridi, 2018) and preferentially utilized by $\mathrm{COX}$ over other fatty acid substrates to produce $\mathrm{PGH}_{2}$. As such the common forms of 'prostacyclin' and 'thromboxane' within the body are derived from coX metabolism of arachidonic acid resulting in 2 double bonds in the alkyl substituents and as such are symbolised as $\mathrm{PGI}_{2}$ and $\mathrm{TXA}_{2}$ respectively. Fish oils contain omega-3 DHA and EPA, which can replace omega-6 
arachidonic acid in cell membranes, increasing the ratio of omega-3:omega- 6 fatty acids, which is associated with cardiovascular protection (Calder, 2017; Innes \& Calder, 2018). This can be modelled in rats fed fish oil supplemented feed for anything from 1 week to 8 months (Chen, et al., 2000; Mclntosh, McLennan, Lawson, Bulman, \& Charnock, 1985) and in mice for 2 weeks (Gong, et al., 2015). In an endotoxemia rat model, continuous enteric feeding with an EPA diet showed its assimilation into tissues was relatively rapid with maximal incorporation seen after 3 days (Palombo, et al., 1996). EPA may be more important than DHA in omega-3 fatty acid preparations for cardiovascular health since the EPA:arachidonic acid ratio is more predictive than the DHA:arachidonic acid ratio with regard to cardiovascular events (Nelson \& Raskin, 2019). Similarly, in clinical formulations DHA but not EPA increases atherogenic LDL levels (Chang, et al., 2018).

Clinical formulations of omega-3 oils include Lovaza ${ }^{\mathrm{TM}}$, which is a combination formulation of ethyl esters of EPA (ethyl EPA also known as icosapent ethyl) and DHA and Vascepa ${ }^{\mathrm{TM}}$ which is a single formulation of ethyl EPA. Lovaza ${ }^{\mathrm{TM}}$ and Vascepa ${ }^{\mathrm{TM}}$ are both used to treat hypertriglyceridemia as an adjunct or substitute to statin therapy although discussion continues regarding the use of ethyl EPA over other regimes such as fibrates (Doggrell, 2019). Most recently, data from the REDUCE-IT trial, which used a higher a dose ( $4 \mathrm{~g} /$ day) than other trials of Vascepa ${ }^{\mathrm{TM}}$, showed that the single ethyl EPA therapy reduced cardiovascular events independently of triglyceride levels (Bhatt, et al., 2019) providing renewed interest in the pleiotropic mechanisms by which fish oils protect the cardiovascular system (Calder, 2017; Nelson \& Raskin, 2019). These potential pleiotropic mechanisms include membrane stabilisation and reduced oxidant stress. Additionally, of relevance to this review, EPA competes with arachidonic acid as a substrate for COX, with greater selectivity towards COX-1 than COX-2 giving rise to $\mathrm{PGH}_{3}$ derived prostanoids including $\mathrm{PGI}_{3}$ and $\mathrm{TXA}_{3}$ (Back, 2017).

Synthetic forms of $\mathrm{PGI}_{3}$ are available commercially making its pharmacology easily accessible and where tested $\mathrm{PGI}_{3}$ and $\mathrm{PGI}_{2}$ elicit equal inhibitory effects on human platelet aggregation (Kobzar, Mardla, Jarving, \& Samel, 2001; Wada, et al., 2007). By contrast, it is commonly reported that $\mathrm{TXA}_{3}$ is less potent an activator of platelet aggregation than TXA (Back, 2017). However, TXA is not commercially available which has made direct pharmacological comparisons with $\mathrm{TXA}_{2}$ difficult. Nevertheless, the fact that EPA shifts the balance of pro-thrombotic TXA 2 towards anti-thrombotic $\mathrm{PGI}_{3}$ is commonly reported and explains, if only in part, the cardio protective effects of fish oil and clinical formulations of EPA. 


\section{Effects of NSAIDs in the cardiovascular system}

As discussed above, low dose aspirin is a popular and important cardio-protective drug because it selectively blocks $C O X-1$ in platelets and reduces the $\mathrm{TXA}_{2}: \mathrm{PGI}_{2}$ balance. However, other drugs in the NSAIDs class are associated with increased risk of cardiovascular side effects including hypertension (White, 2007), stroke (Fanelli, Ghisi, Aprile, \& Lapi, 2017), heart attacks (McGettigan \& Henry, 2011) and heart failure (Ungprasert, Srivali, \& Kittanamongkolchai, 2015).

Cardiovascular side effects were initially thought to be limited to COX-2 selective drugs such as rofecoxib and celecoxib introduced 20 years ago. However, after almost 20 years of clinical evidence (McGettigan \& Henry, 2011; Pirlamarla \& Bond, 2016) addressing cardiovascular side effects in NSAID users we now know that all NSAIDs are associated with risk. This is not only evidenced by systematic review and meta-analysis but by two large clinical cardiovascular outcome studies, SCOT (T. M. MacDonald, et al., 2016) and PRECISION (Nissen, et al., 2016), that showed that traditional NSAIDs, including ibuprofen and naproxen, carry at least as great a cardiovascular risk as the COX-2 selective drug celecoxib, with ibuprofen emerging as significantly more toxic to the kidney at therapeutic doses (Nissen, et al., 2016). Importantly, the increased risk of cardiovascular events whilst on NSAIDs, including ibuprofen, can be seen after only 1-2 weeks of regular use (Bally, et al., 2017).

The context and scale of NSAID associated cardiovascular side effects in the population (Mitchell \& Kirkby, 2019), their unintended impact on opioid use (Stokes, Berry, Hempstead, Lundberg, \& Neogi, 2019) and the missed opportunity to prevent cancer (Mitchell \& Kirkby, 2019) are discussed elsewhere and together highlight the need for continued research in the area. However, the specific downstream mechanisms by which NSAIDs cause cardiovascular side effects are incompletely understood but it is clear that blocking COX-2 is the fulcrum and that incidental blockade of COX-1 by traditional NSAIDs does not mitigate the risk of cardiovascular side effects. Explaining this is difficult and needs to take account of (i) the specific role that COX-1 versus COX-2 plays in $\mathrm{PGI}_{2}$ formation (discussed in detail below), (ii) the $\mathrm{PGI}_{2}: \mathrm{TXA}_{2}$ balance (discussed above) and (iii) the potential for $\mathrm{PGI}_{2}$ to act as a constrictor in some vascular beds in some settings. This last point is covered in detail elsewhere (S. Khan, Andrews, \& Chin-Dusting, 2019; Luo, et al., 2016) and discussed briefly below. Finally, it should also be noted that blocking COX enzymes can result in shunting of the substrate arachidonic acid to other enzyme pathways, such as 5-lipoxygenase (5-LOX). 5-LOX is 
expressed in leukocytes and utilizes arachidonic acid to produce leukotriene A4 (LTA $)$ (Dennis \& Norris, 2015; Martel-Pelletier, Lajeunesse, Reboul, \& Pelletier, 2003). While vascular cells do not contain 5-LOX, endothelial cells can metabolise $\mathrm{LTA}_{4}$ to $\mathrm{LTC}_{4}, \mathrm{LTB}_{4}, \mathrm{LTD}$, and $\mathrm{LTE}_{4}$. $\mathrm{LTs}$ are implicated in the pathological processes associated with atherosclerosis and inflammation(de Gaetano, Donati, \& Cerletti, 2003). Thus, blocking COX with NSAIDs could result in the shunting of arachidonic towards $\mathrm{LTC}_{4}$ in immune cells and on to other LTs in endothelial cells, potentially contributing to the cardiovascular side effects seen with NSAIDs. While the importance of this pathway in the cardiovascular effects caused by NSAIDs remains unclear, the use of combined COX/LOX inhibitor drugs may offer therapeutic solutions to some of the side effects caused by blocking COX-2 (MartelPelletier, et al., 2003).

\section{Mechanisms by which cyclooxygenase protects the cardiovascular system}

\section{1. $\quad \operatorname{coX}-1$}

As discussed above, COX-1 is expressed throughout the vasculature (Zidar, et al., 2009) where it produces largely $\mathrm{PGl}_{2}$. However, a protective vasodilator or anti-thrombotic role of endogenous $\mathrm{PGI}_{2}$ has been difficult to demonstrate in humans in vivo. This is because global peripheral endothelial dependent vasodilation and thrombotic tone are difficult to faithfully measure in humans and because COX-1 drives prostacyclin and the counter, vasoconstrictor, pro-thrombotic hormone, TXA 2 . In terms of vascular responses, a vasodilator function of endogenous $\mathrm{PGI}_{2}$ has been inferred in studies using flow-mediated vasodilation measured at the brachial artery after acute dosing with NSAIDs. For example, acutely inhibiting COX with traditional NSAIDs that block COX-1 as well as COX-2 including aspirin, indomethacin, diclofenac, naproxen or piroxicam reduced flow-mediated dilatation (reactive hyperaemia) in humans, particularly at the peak of the response (Carlsson, Sollevi, \& Wennmalm, 1987; Carlsson \& Wennmalm, 1983; Engelke, Halliwill, Proctor, Dietz, \& Joyner, 1996; Kilbom \& Wennmalm, 1976; Wilson \& Kapoor, 1993). However, locally infused aspirin did not inhibit forearm blood flow stimulated by bradykinin in healthy volunteers (Benjamin, et al., 1989). By contrast, in healthy volunteers, aspirin (Noon, Walker, Hand, \& Webb, 1998) or diclofenac (Hojs, Strucl, \& Cankar, 2009) reduced acetylcholine induced micro vascular vasodilatation in the skin. However, protocols that used longer duration of dosing and/or selective COX-2 inhibitors have produced mixed results. Flow mediated dilation in osteoarthritis patients was not affecting by naproxen or diclofenac after 7 days of dosing (Solmaz, et al., 2012). In addition, neither naproxen nor rofecoxib affected flow mediated or acetylcholine induced increases in forearm blood flow in healthy
Formatted: Subscript

Formatted: Subscript 
volunteers after 7 days of dosing (Verma, Raj, Shewchuk, Mather, \& Anderson, 2001). Furthermore, in both hypertensive subjects (Widlansky, et al., 2003) and subjects with peripheral arterial disease (Florez, et al., 2009) celecoxib actually increased flow-mediated dilatation after acute (3 hours) or longer term ( 7 days) of dosing.

In terms of thrombosis, there is no clinical evidence that selectively blocking COX-1 mediated-PGI 2 release increases thrombosis. This is likely because there are no drugs currently in use that selectively target endothelial COX-1 and so there are no pharmacological means of selectively blocking COX-1 mediated $\mathrm{PGI}_{2}$ release. In animal models, selective COX-1 inhibitors or global COX-1 knockout where both $\mathrm{PGI}_{2}$ and $\mathrm{TXA}_{2}$ are blocked the overriding phenotype is dictated by loss of TXA (rather than loss of $\mathrm{PGI}_{2}$ ) resulting in reduced thrombosis. However, recent work from our group using endothelial cell-specific COX-1 knockout mice has demonstrated that selective loss of prostacyclin increases thrombosis, thereby confirming that systemic COX-1 derived $\mathrm{PGI}_{2}$ formation provides an endogenous homeostatic brake on platelet activation (Mitchell, et al., 2019). The clinical translation of this work is likely relevant in ageing where TXA 2 levels increase with age (lyer \& Dayal, 2019) whilst circulating levels of the $\mathrm{PGI}_{2}$ (measured as the breakdown product as 6-keto $\mathrm{PGF}_{1 \alpha}$ ) decreases from $400 \mathrm{pg} / \mathrm{ml}$ in new born infants, to $230 \mathrm{pg} / \mathrm{ml}$ in infants, $150 \mathrm{pg} / \mathrm{ml}$ in adolescents, and $85 \mathrm{pg} / \mathrm{ml}$ in adults (Kaapa, Viinikka, \& Ylikorkala, 1982). Age related loss of plasma levels of $\mathrm{PGI}_{2}$ is not due to reduced COX-1 or PGIS expression but is suggested to be caused by accelerated degradation (Qian, Luo, \& Chi, 2012).

\section{2. $\quad$ COX-2}

A cardio-protective role of COX-2 is easily demonstrated as discussed above in numerous clinical studies, systematic reviews and meta-analysis. Moreover, inhibition or genetic deletion of COX-2 in mice causes increased thrombosis (Mitchell, et al., 2019; Yu, et al., 2012), decreased bleeding time (Cheng, et al., 2006), reduced renal function (Ahmetaj-Shala, et al., 2015; Kirkby, et al., 2019; M. Z. Zhang, et al., 2015), increased blood pressure (Ahmetaj-Shala, et al., 2015; Cheng, et al., 2006) and (in some models) accelerated atherosclerosis (Kirkby, et al., 2014; Tang, et al., 2014). However, COX2 is not normally expressed within the systemic vasculature (Kirkby, et al., 2012) and is not linked to vascular $\mathrm{PGI}_{2}$ production (Kirkby, et al., 2012; Kirkby, et al., 2013; Li, et al., 2016; Liu, et al., 2012) or plasma levels of $\mathrm{PGI}_{2}$ (Kirkby, et al., 2014; Kirkby, et al., 2013). Whereas, COX-2 is constitutively expressed in select structures and regions of the body. These include (i) kidney, (ii) some vessels, (iii) gut, (iv) thymus and (v) brain (Mitchell \& Kirkby, 2019). The concept of organ crosstalk in 
cardiovascular disease is now well established and whilst we do not yet fully understand the mechanisms by which COX-2 protects the cardiovascular system and thereby how inhibition of COX2 by NSAIDs causes cardiovascular side effects, hypothesis can, and have been, generated to explain how COX-2 in remote regions could function to maintain cardiovascular health. The role that COX-2, identified in tissues outside the traditional cardiovascular system, may play in cardiovascular health is discussed below and summarised in Table 1 and Figure 2.

\subsubsection{Kidney}

Inhibition of COX-2 in the kidney as a contributory mechanism to explain the cardiovascular risk associated with NSAIDs is not new. The well-established role of the kidney in controlling blood pressure means that renal physiology and pharmacology is central to most common cardiovascular diseases. COX-2 is expressed constitutively in the kidney, including within the medulla interstitial fibroblasts, tubular epithelial cells and renal endothelial cells (Harris, 2006; Komhoff, Grone, Klein, Seyberth, \& Nusing, 1997; Radi \& Khan, 2019) where its expression is driven by the transcription factor, NFAT (Kirkby, et al., 2016). Constitutive COX-2 in the kidney regulates fundamental aspects of renal homeostasis including renal hemodynamics, body water and sodium balance, renin release and angiotensin II formation. Inhibition of renal COX-2 with NSAIDs therefore increases blood pressure (Harris, 2006). Of note, in a systematic analysis of regional blood flow, we found that of all of the regions where COX-2 is expressed constitutively, blood flow is only demonstrably reduced, by acute COX-2 inhibition, in the kidney (Mitchell, et al., 2018).

In addition to established renal pathways we have identified $>1000$ genes altered in the renal medulla of germ line COX-2 knockout mice. Within this large set were genes encoding proteins important for multiple cardiovascular pathways including systemic blood pressure regulation, blood vessel size regulation, angiotensin and endothelin-1 biosynthesis, and nitric oxide (NO) and methylarginine biosynthesis (Ahmetaj-Shala, et al., 2015). Methylarginines, including asymmetric dimethylarginine (ADMA), are endogenous inhibitors of endothelial NO synthase (eNOS) and have previously been suggested as potential contributors to the cardiovascular side effects caused by NSAIDs (Fosslien, 2005). There is strong precedence for this suggestion since ADMA is increased in both early and end stage kidney disease (Sitar, 2016) and is a biomarker of cardiovascular disease (Schlesinger, Sonntag, Lieb, \& Maas, 2016). Moreover, the COX inhibitor indomethacin reduces DDAH (which metabolises ADMA) expression and increases ADMA levels in gastric tissue in rats (Shahin, Abdelkader, \& Safar, 
2018; L. Wang, et al., 2008) while the $\mathrm{PGI}_{2}$ drug iloprost reduces plasma levels of ADMA in patients with peripheral vascular disease (Blardi, et al., 2006) or Burger's Disease (Senol \& Senol, 2017). In support of the suggestion by Fosslien (Fosslien, 2005), we found that PRMT1 (which synthesizes ADMA) was increased whilst genes responsible for ADMA removal (DDAH1 and AGXT2) were reduced in kidneys from COX-2 knockout mice. In line with this, we found that ADMA levels were increased in the plasma of COX-2 knockout mice and in healthy volunteers taking naproxen or celecoxib. Further recent work from our group has validated these observations showing that pharmacological inhibition of COX-2 in mice using parecoxib increases plasma ADMA and that this is associated with $\mathrm{PGI}_{2}$ but not $\mathrm{PGE}_{2}$ signaling (Kirkby, et al., 2019).

In our studies we used models of COX-2 deletion or pharmacological inhibition in mice or in human subjects where blood pressure was increased and/or renal function was reduced. This seems to be an important factor in the COX-2/ADMA axis since ADMA was only increased in arthritic rats by diclofenac (which increased blood pressure) but not celecoxib (which in their study did not increase blood pressure) (Verhoeven, et al., 2017) and because in models where COX-2 was inhibited or knocked out post-natally and which displayed normal blood pressure and/or renal function, ADMA was not increased (Ricciotti, et al., 2018). Taken together these studies further support a role for renal COX-2 in any associated elevation in plasma ADMA caused by NSAIDs; this is entirely in line with the recognized role that kidney COX-2 plays in cardiovascular protection (Walker \& Biasucci, 2018).

Finally, we found a functional indication for increased ADMA in COX-2 knockout mice since eNOS responses in aorta were reduced (Ahmetaj-Shala, et al., 2015) despite normal levels of local $\mathrm{PGI}_{2}$ production. Others have also found that aortas from COX-2 knockout mice have reduced eNOS responses but in those studies this was attributed to reduced eNOS expression (Yu, et al., 2012). eNOS is present in the endothelium of all blood vessels where its basal activity protects the cardiovascular system from atherosclerosis, thrombosis and hypertension. $\mathrm{NO}$ and $\mathrm{PGI}_{2}$ have common protective effects in the cardiovascular system where they work additively to relax blood vessels (Lidbury, Antunes, de Nucci, \& Vane, 1989) and synergistically to inhibit platelet aggregation (Kirkby, et al., 2013; Levin, Weksler, \& Jaffe, 1982; Lidbury, et al., 1989; P. S. Macdonald, Read, \& Dusting, 1988; Radomski, Palmer, \& Moncada, 1987).

\subsubsection{Endothelium}


The idea that COX-2 in endothelial cells produces $\mathrm{PGI}_{2}$ and that inhibition of COX-2 in these cells accounts for the cardiovascular side effects caused by NSAIDs is frequently advanced, although the relative contribution of systemic versus regional vascular COX-2 to protecting the cardiovascular system remains the subject of debate (Funk \& FitzGerald, 2007; Mitchell \& Kirkby, 2019; Yu, Ricciotti, Grosser, \& Fitzgerald, 2009). Nevertheless, while in general terms COX-2 (in comparison with COX-1) is only sparsely expressed in most areas of endothelium, where its activity has little impact on gross levels of $\mathrm{PGI}_{2}$ formation in vitro and in vivo (Kirkby, et al., 2012; Kirkby, et al., 2013; Liu, et al., 2012), endothelial COX-2 does protect the cardiovascular system. For example, in genetically modified mice where COX-2 is selectively knocked out of endothelial cells, thrombosis (Mitchell, et al., 2019; Yu, et al., 2012) and atherosclerosis (Tang, et al., 2014) are increased while deletion of COX-2 from endothelial cells and vascular smooth muscle increases blood pressure (Yu, et al., 2012). However, it is not yet clear where the cardio-protective endothelial COX-2 is expressed or how $\mathrm{PGI}_{2}$ derived from COX-2 and COX-1 operates separately and together to maintain cardiovascular health.

\subsubsection{Gut}

A role for inhibition of COX-2 in the gut as a contributing factor to NSAID-associated cardiovascular side effects has yet to be fully explored. However, several pieces of evidence support the hypothesis. Firstly, COX-2 is co-expressed with COX-1 in the gut where both isoforms contribute to gastrointestinal protection (Wallace, McKnight, Reuter, \& Vergnolle, 2000) since traditional NSAIDs and (albeit to a less extent) selective COX-2 inhibitors cause increased risk of gastrointestinal events (Coxib, et al., 2013). Secondly NSAIDs can increase gut permeability (Bjarnason, Williams, Smethurst, Peters, \& Levi, 1986; Sigthorsson, et al., 1998) and cause subclinical increases in circulating bacterial LPS in rats (Tugendreich, Pearson, Sagartz, Jarnagin, \& Kolaja, 2006) and humans (athletes) (Nieman, et al., 2006) resulting in 'metabolic endotoxemia' (Marlicz, Loniewski, Grimes, \& Quigley, 2014). Thirdly, metabolic endotoxemia primes the cardiovascular system to inflammation and is associated with increased risk of a wide range of cardiovascular diseases (Charalambous, Stephens, Feavers, \& Montgomery, 2007; Marlicz, et al., 2014; Wiedermann, et al., 1999). However, complicating this idea is the fact that selective COX-2 inhibitors, which carry similar risk of cardiovascular side effects to traditional NSAIDs, are associated with reduced gastrointestinal side effects (Coxib, et al., 2013) and (for celecoxib) produce fewer small bowel lesions (Goldstein, et al., 2005) than traditional NSAIDs. 


\subsubsection{Thymus}

The case for COX-2 in the thymus as a direct and significant contributor to cardiovascular protection is relatively nebulous although some lines of evidence do exist. Firstly, COX-2 is expressed selectively in medullary epithelial cells of the human thymus where it may influence immature $\mathrm{CD} 4^{+}$and $\mathrm{CD}^{+}$thymocytes (Rocca, et al., 2002). Secondly, immune cell regulation by the thymus is important in atherosclerosis (Dai, Zhang, Wang, Wu, \& Liang, 2018; Tse, Tse, Sidney, Sette, \& Ley, 2013). Thirdly, COX-2 knockout mice have increased atherosclerosis associated with accumulation of T-lymphocytes in atherosclerotic plaques (Kirkby, et al., 2014). Finally, a link between immunomodulation towards a Th1 response and plaque instability as a mechanism to explain cardiovascular side effects caused by COX-2 inhibitors has been suggested (Padol \& Hunt, 2010).

\subsubsection{Brain}

COX-2 is constitutively expressed throughout the central nervous system where its activity contributes to fundamental brain functions including synaptic activity, memory and functional hyperaemia. NSAIDs cross the blood brain barrier (Dembo, Park, \& Kharasch, 2005; Parepally, Mandula, \& Smith, 2006) and much has been made of the inflammatory effects of COX-2 in the brain with a large body of unresolved literature that implicates a therapeutic role for NSAIDs in degenerative conditions such as Alzheimer Disease (Guan \& Wang, 2019; Trepanier \& Milgram, 2010). However, despite the importance of the central nervous system in regulating blood pressure (Wyss \& Carlson, 1999) and cardiovascular homeostasis (Tahsili-Fahadan \& Geocadin, 2017) a firm link with NSAIDs acting on central COX-2 to cause cardiovascular side effects has not been made. Nevertheless, oral administration of indomethacin in healthy volunteers reduces cerebral blood flow, which may be therapeutically useful in the treatment of traumatic brain injury (Slavik \& Rhoney, 1999). In addition, early studies in rats showed that intracerebroventricular administration of the most abundant prostanoid in the brain, $\mathrm{PGD}_{2}$, did not affect blood pressure (Siren, 1982a). Others showed that arachidonic acid, $\mathrm{PGF}_{2 \alpha}$ (Siren, 1982b) or $\mathrm{PGE}_{2}$ increased blood pressure while $\mathrm{PGI}_{2}$ reduced blood pressure and the NSAID indomethacin had no effect (Kondo, Okuno, Saruta, \& Kato, 1979). In separate studies, intracerebroventricular administration of the NSAIDs ketorolac or meclofenamate blocked the excitatory cardiovascular and renal sympathetic responses to circulating TNF $\alpha$ (Z. H. Zhang, Wei, Francis, \& Felder, 2003) and the pressor effects of angiotensin II (Inoue, Crofton, \& Share, 1990), respectively. Conditional neuronal COX-2 knockout mice have been made (Vardeh, et al., 2009), but have not as yet been used in cardiovascular models. 


\begin{tabular}{|l|l|}
\hline Tissue & $\begin{array}{l}\text { Example hypothesis attributed to 'tissue hot spot' COX-2 expression and } \\
\text { cardiovascular health/disease }\end{array}$ \\
\hline Kidney & $\begin{array}{l}\text { "COX-2 in the kidney protects the cardiovascular by restraining blood pressure and } \\
\text { limiting circulating levels of hypertensive mediates such as ADMA" }\end{array}$ \\
\hline Endothelium & $\begin{array}{l}\text { "Endothelial COX-2 drives production of the protective, anti-thrombotic hormone } \\
\text { prostacyclin and its inhibition to increased thrombosis" }\end{array}$ \\
\hline Gut & $\begin{array}{l}\text { "COX-2 inhibition increases gut permeability leading to metabolic endotoxemia } \\
\text { (subclinical, chromic increased plasma bacteria/LPS) and increased cardiovascular }\end{array}$ \\
\hline Thymus & $\begin{array}{l}\text { "COX-2 inhibition in the thymus discupts the balance of T cells accelerating } \\
\text { atherosclerosis' }\end{array}$ \\
\hline Brain & $\begin{array}{l}\text { "COX-2 inhibition in the brain disrupts central control of cardiovascular } \\
\text { homeostasis leading to increased blood pressure" }\end{array}$ \\
\hline
\end{tabular}

Table 1. Hypotheses for how distant COX-2 in particular organ systems could provide systemic cardiovascular protection.

\section{Summary and future directions}

COX and the $\mathrm{PGI}_{2}: \mathrm{TXA}_{2}$ balance is fundamental to cardiovascular health and disease. Drugs that work by manipulating this balance towards cardiovascular protection such as aspirin, $\mathrm{PGI}_{2}, \mathrm{PGE}_{1}$ and $\mathrm{EPA}$ protect millions from cardiovascular disease around the world, although the full potential of harnessing this protective pathway has yet to be realized. As we learn more, using tools such as cell specific knockout and transgenic mouse models in conjunction with increased availability of human omic data relevant for personalized medicine, new cardio-protective drugs based on this pathway will be developed. Just as important to understand and mitigate are the cardiovascular side effects caused by inhibiting COX-2 with NSAIDs. NSAIDs are critically important pain medications, with aspirin and ibuprofen, listed in the World Health Organization list of essential medicines. Some drugs in this class can also reduce cancer risk but are not used because of concerns about side effects. To develop improved therapeutics we need to understand the mechanisms by which COX-2 protects the cardiovascular system and so identify biomarkers of those most at risk. With this knowledge we can design new drug combinations/formulations that retain efficacy against pain and inflammation with reduced cardiovascular side effects. 


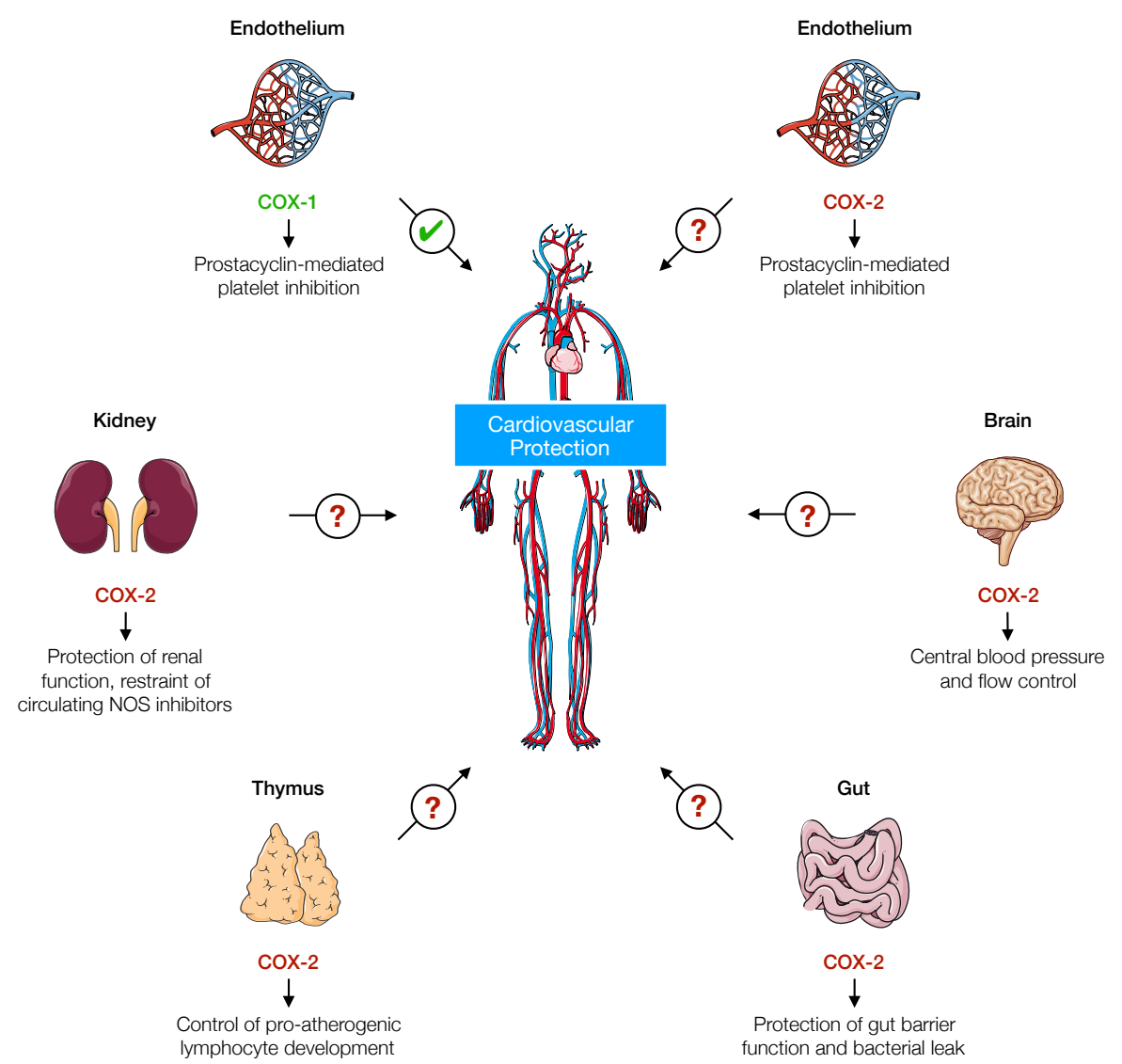

Figure 2. Potential mechanisms of COX-1- and COX-2-mediated cardiovascular protection arising from local expression in discrete organ systems.

\section{Funding}

Authors are recipients of awards from the British Heart Foundation (JAM and NSK, RG/18/4/33541;

RV, FS/19/6/34129; NSK, FS/16/1/31699; TDW, PG/15/47/31591, PG/15/79/31777, and PG/17/40/33028) and BA-J is a recipient of a Wellcome Trust Institutional Strategic Support Fund Springboard Fellowship. The funders had no role in the study design, data analysis, data interpretation or writing of the report. 


\section{Conflict of Interest Statement}

Within the past 5 years, JAM is a member of the scientific advisory board of Antibe Therapeutics Inc and has received contributions including 'in kind' from Gesynta Pharma AB, Actelion and Merck Sharp \& Dohme Limited. Other authors declare no conflicts of interest to declare. 


\section{References}

Ahmetaj-Shala, B., Kirkby, N. S., Knowles, R., Al'Yamani, M., Mazi, S., Wang, Z., Tucker, A. T., Mackenzie, L., Armstrong, P. C., Nusing, R. M., Tomlinson, J. A., Warner, T. D., Leiper, J., \& Mitchell, J. A. (2015). Evidence that links loss of cyclooxygenase-2 with increased asymmetric dimethylarginine: novel explanation of cardiovascular side effects associated with anti-inflammatory drugs. Circulation, 131, 633-642.

Akopov, S. E., Orekhov, A. N., Tertov, V. V., Khashimov, K. A., Gabrielyan, E. S., \& Smirnov, V. N. (1988). Stable analogues of prostacyclin and thromboxane A2 display contradictory influences on atherosclerotic properties of cells cultured from human aorta. The effect of calcium antagonists. Atherosclerosis, 72, 245-248.

Alexander, S. P. H., Christopoulos, A., Davenport, A. P., Kelly, E., Mathie, A., Peters, J. A., Veale, E. L., Armstrong, J. F., Faccenda, E., Harding, S. D., Pawson, A. J., Sharman, J. L., Southan, C., Davies, J. A., \& Collaborators, C. (2019). THE CONCISE GUIDE TO PHARMACOLOGY 2019/20: G protein-coupled receptors. Br J Pharmacol, 176 Suppl 1, S21-S141.

Ali, F. Y., Armstrong, P. C., Dhanji, A. R., Tucker, A. T., Paul-Clark, M. J., Mitchell, J. A., \& Warner, T. D. (2009). Antiplatelet actions of statins and fibrates are mediated by PPARs. Arterioscler Thromb Vasc Biol, 29, 706-711.

Ali, F. Y., Hall, M. G., Desvergne, B., Warner, T. D., \& Mitchell, J. A. (2009). PPARbeta/delta agonists modulate platelet function via a mechanism involving PPAR receptors and specific association/repression of PKCalpha--brief report. Arterioscler Thromb Vasc Biol, 29, 18711873.

Aoyama, T., Yui, Y., Morishita, H., \& Kawai, C. (1990). Prostaglandin 12 half-life regulated by high density lipoprotein is decreased in acute myocardial infarction and unstable angina pectoris. Circulation, 81, 1784-1791.

Azizkhan, J. C., Jensen, D. E., Pierce, A. J., \& Wade, M. (1993). Transcription from TATA-less promoters: dihydrofolate reductase as a model. Crit Rev Eukaryot Gene Expr, 3, 229-254.

Back, M. (2017). Omega-3 fatty acids in atherosclerosis and coronary artery disease. Future Sci OA, 3, FSO236.

Baldenkov, G. N., Akopov, S. E., Ryong, L. H., \& Orekhov, A. N. (1988). Prostacyclin, thromboxane A2 and calcium antagonists: effects on atherosclerotic characteristics of vascular cells. Biomed Biochim Acta, 47, S324-327.

Bally, M., Dendukuri, N., Rich, B., Nadeau, L., Helin-Salmivaara, A., Garbe, E., \& Brophy, J. M. (2017). Risk of acute myocardial infarction with NSAIDs in real world use: bayesian meta-analysis of individual patient data. BMJ, 357, j1909.

Belvisi, M. G., \& Mitchell, J. A. (2009). Targeting PPAR receptors in the airway for the treatment of inflammatory lung disease. BrJ Pharmacol, 158, 994-1003.

Benjamin, N., Cockcroft, J. R., Collier, J. G., Dollery, C. T., Ritter, J. M., \& Webb, D. J. (1989). Local inhibition of converting enzyme and vascular responses to angiotensin and bradykinin in the human forearm. J Physiol, 412, 543-555.

Bergqvist, F., Morgenstern, R., \& Jakobsson, P. J. (2019). A review on mPGES-1 inhibitors: From preclinical studies to clinical applications. Prostaglandins Other Lipid Mediat, 147, 106383.

Bhatt, D. L., Steg, P. G., Miller, M., Brinton, E. A., Jacobson, T. A., Ketchum, S. B., Doyle, R. T., Jr., Juliano, R. A., Jiao, L., Granowitz, C., Tardif, J. C., Ballantyne, C. M., \& Investigators, R.-I. (2019). Cardiovascular Risk Reduction with Icosapent Ethyl for Hypertriglyceridemia. N Engl J Med, 380, 11-22.

Bishop-Bailey, D. (2015). Nuclear receptors in vascular biology. Curr Atheroscler Rep, 17, 507. 
Bjarnason, I., Williams, P., Smethurst, P., Peters, T. J., \& Levi, A. J. (1986). Effect of non-steroidal anti-inflammatory drugs and prostaglandins on the permeability of the human small intestine. Gut, 27, 1292-1297.

Blardi, P., de Lalla, A., Pieragalli, D., De Franco, V., Meini, S., Ceccatelli, L., \& Auteri, A. (2006). Effect of iloprost on plasma asymmetric dimethylarginine and plasma and platelet serotonin in patients with peripheral arterial occlusive disease. Prostaglandins Other Lipid Mediat, 80, 175-182.

Bryant, C. E., Appleton, I., \& Mitchell, J. A. (1998). Vascular endothelial growth factor upregulates constitutive cyclooxygenase 1 in primary bovine and human endothelial cells. Life Sci, 62, 2195-2201.

Calder, P. C. (2017). Omega-3 fatty acids and inflammatory processes: from molecules to man. Biochem Soc Trans, 45, 1105-1115.

Carlsson, I., Sollevi, A., \& Wennmalm, A. (1987). The role of myogenic relaxation, adenosine and prostaglandins in human forearm reactive hyperaemia. J Physiol, 389, 147-161.

Carlsson, I., \& Wennmalm, A. (1983). Effect of different prostaglandin synthesis inhibitors on postocclusive blood flow in human forearm. Prostaglandins, 26, 241-252.

Chandrasekharan, N. V., Dai, H., Roos, K. L., Evanson, N. K., Tomsik, J., Elton, T. S., \& Simmons, D. L. (2002). COX-3, a cyclooxygenase-1 variant inhibited by acetaminophen and other analgesic/antipyretic drugs: cloning, structure, and expression. Proc Natl Acad Sci U S A, 99, 13926-13931.

Chang, C. H., Tseng, P. T., Chen, N. Y., Lin, P. C., Lin, P. Y., Chang, J. P., Kuo, F. Y., Lin, J., Wu, M. C., \& Su, K. P. (2018). Safety and tolerability of prescription omega-3 fatty acids: A systematic review and meta-analysis of randomized controlled trials. Prostaglandins Leukot Essent Fatty Acids, 129, 1-12.

Charalambous, B. M., Stephens, R. C., Feavers, I. M., \& Montgomery, H. E. (2007). Role of bacterial endotoxin in chronic heart failure: the gut of the matter. Shock, 28, 15-23.

Chen, L. Y., Jokela, R., Li, D. Y., Bavry, A. A., Sandler, H., Sjoquist, M., Saldeen, T., \& Mehta, J. L. (2000). Effect of stable fish oil on arterial thrombogenesis, platelet aggregation, and superoxide dismutase activity. J Cardiovasc Pharmacol, 35, 502-505.

Cheng, Y., Wang, M., Yu, Y., Lawson, J., Funk, C. D., \& Fitzgerald, G. A. (2006). Cyclooxygenases, microsomal prostaglandin E synthase-1, and cardiovascular function. J Clin Invest, 116, 1391-1399.

Christ-Hazelhof, E., \& Nugteren, D. H. (1981). Prostacyclin is not a circulating hormone. Prostaglandins, 22, 739-746.

Coxib, traditional, N. T. C., Bhala, N., Emberson, J., Merhi, A., Abramson, S., Arber, N., Baron, J. A., Bombardier, C., Cannon, C., Farkouh, M. E., FitzGerald, G. A., Goss, P., Halls, H., Hawk, E., Hawkey, C., Hennekens, C., Hochberg, M., Holland, L. E., Kearney, P. M., Laine, L., Lanas, A., Lance, P., Laupacis, A., Oates, J., Patrono, C., Schnitzer, T. J., Solomon, S., Tugwell, P., Wilson, K., Wittes, J., \& Baigent, C. (2013). Vascular and upper gastrointestinal effects of non-steroidal anti-inflammatory drugs: meta-analyses of individual participant data from randomised trials. Lancet, 382, 769-779.

Crescente, M., Menke, L., Chan, M. V., Armstrong, P. C., \& Warner, T. D. (2019). Eicosanoids in platelets and the effect of their modulation by aspirin in the cardiovascular system (and beyond). Br J Pharmacol, 176, 988-999.

Dai, X., Zhang, D., Wang, C., Wu, Z., \& Liang, C. (2018). The Pivotal Role of Thymus in Atherosclerosis Mediated by Immune and Inflammatory Response. Int J Med Sci, 15, 15551563. 
de Gaetano, G., Donati, M. B., \& Cerletti, C. (2003). Prevention of thrombosis and vascular inflammation: benefits and limitations of selective or combined COX-1, COX-2 and 5-LOX inhibitors. Trends Pharmacol Sci, 24, 245-252.

de Nucci, G., Gryglewski, R. J., Warner, T. D., \& Vane, J. R. (1988). Receptor-mediated release of endothelium-derived relaxing factor and prostacyclin from bovine aortic endothelial cells is coupled. Proc Natl Acad Sci U S A, 85, 2334-2338.

Dembo, G., Park, S. B., \& Kharasch, E. D. (2005). Central nervous system concentrations of cyclooxygenase-2 inhibitors in humans. Anesthesiology, 102, 409-415.

Dennis, E. A., \& Norris, P. C. (2015). Eicosanoid storm in infection and inflammation. Nat Rev Immunol, 15, 511-523.

Doggrell, S. A. (2019). Clinical trials of eicosapentaenoic acid (EPA) prescription products for the treatment of hypertriglyceridemia. Expert Opin Pharmacother, 20, 1221-1225.

Dusting, G. J., Moncada, S., \& Vane, J. R. (1978). Recirculation of prostacyclin (PGI2) in the dog. $\mathrm{Br} J$ Pharmacol, 64, 315-320.

Engelke, K. A., Halliwill, J. R., Proctor, D. N., Dietz, N. M., \& Joyner, M. J. (1996). Contribution of nitric oxide and prostaglandins to reactive hyperemia in human forearm. J Appl Physiol (1985), 81, 1807-1814.

Fanelli, A., Ghisi, D., Aprile, P. L., \& Lapi, F. (2017). Cardiovascular and cerebrovascular risk with nonsteroidal anti-inflammatory drugs and cyclooxygenase 2 inhibitors: latest evidence and clinical implications. Ther Adv Drug Saf, 8, 173-182.

Florez, A., de Haro, J., Martinez, E., Varela, C., Bleda, S., \& Acin, F. (2009). Selective cyclooxygenase2 inhibition reduces endothelial dysfunction and improves inflammatory status in patients with intermittent claudication. Rev Esp Cardiol, 62, 851-857.

Flower, R. J., \& Blackwell, G. J. (1976). The importance of phospholipase-A2 in prostaglandin biosynthesis. Biochem Pharmacol, 25, 285-291.

Fosslien, E. (2005). Cardiovascular complications of non-steroidal anti-inflammatory drugs. Ann Clin Lab Sci, 35, 347-385.

Funk, C. D., \& FitzGerald, G. A. (2007). COX-2 inhibitors and cardiovascular risk. J CardiovasC Pharmacol, 50, 470-479.

Garavito, R. M., Malkowski, M. G., \& DeWitt, D. L. (2002). The structures of prostaglandin endoperoxide $\mathrm{H}$ synthases-1 and -2. Prostaglandins Other Lipid Mediat, 68-69, 129-152.

Goldstein, J. L., Eisen, G. M., Lewis, B., Gralnek, I. M., Zlotnick, S., Fort, J. G., \& Investigators. (2005). Video capsule endoscopy to prospectively assess small bowel injury with celecoxib, naproxen plus omeprazole, and placebo. Clin Gastroenterol Hepatol, 3, 133-141.

Gong, Y., Lin, M., Piao, L., Li, X., Yang, F., Zhang, J., Xiao, B., Zhang, Q., Song, W. L., Yin, H., Zhu, L., Funk, C. D., \& Yu, Y. (2015). Aspirin enhances protective effect of fish oil against thrombosis and injury-induced vascular remodelling. Br J Pharmacol, 172, 5647-5660.

Guan, P. P., \& Wang, P. (2019). Integrated communications between cyclooxygenase-2 and Alzheimer's disease. FASEB J, 33, 13-33.

Hajjar, D. P., Weksler, B. B., Falcone, D. J., Hefton, J. M., Tack-Goldman, K., \& Minick, C. R. (1982). Prostacyclin modulates cholesteryl ester hydrolytic activity by its effect on cyclic adenosine monophosphate in rabbit aortic smooth muscle cells. J Clin Invest, 70, 479-488.

Harris, R. C. (2006). COX-2 and the kidney. J Cardiovasc Pharmacol, 47 Suppl 1, S37-42.

Harris, R. C., McKanna, J. A., Akai, Y., Jacobson, H. R., Dubois, R. N., \& Breyer, M. D. (1994)

Cyclooxygenase- 2 is associated with the macula densa of rat kidney and increases with salt restriction. J Clin Invest, 94, 2504-2510. 
Hashemi Goradel, N., Najafi, M., Salehi, E., Farhood, B., \& Mortezaee, K. (2019). Cyclooxygenase-2 in cancer: A review. J Cell Physiol, 234, 5683-5699.

Heavey, D. J., Barrow, S. E., Hickling, N. E., \& Ritter, J. M. (1985). Aspirin causes short-lived inhibition of bradykinin-stimulated prostacyclin production in man. Nature, 318, 186-188.

Hojs, N., Strucl, M., \& Cankar, K. (2009). The effect of glibenclamide on acetylcholine and sodium nitroprusside induced vasodilatation in human cutaneous microcirculation. Clin Physiol Funct Imaging, 29, 38-44.

Innes, J. K., \& Calder, P. C. (2018). The Differential Effects of Eicosapentaenoic Acid and Docosahexaenoic Acid on Cardiometabolic Risk Factors: A Systematic Review. Int J Mol Sci, 19.

Inoue, M., Crofton, J. T., \& Share, L. (1990). Interactions between the brain renin-angiotensin system and brain prostanoids in the control of vasopressin secretion. Exp Brain Res, 83, 131 136.

Iyer, K. S., \& Dayal, S. (2019). Modulators of platelet function in aging. Platelets, 1-9.

Kaapa, P., Viinikka, L., \& Ylikorkala, O. (1982). Plasma prostacyclin from birth to adolescence. Arch Dis Child, 57, 459-461.

Kang, Y. J., Mbonye, U. R., DeLong, C. J., Wada, M., \& Smith, W. L. (2007). Regulation of intracellular cyclooxygenase levels by gene transcription and protein degradation. Prog Lipid Res, 46, 108-125.

Khan, S., Andrews, K. L., \& Chin-Dusting, J. P. F. (2019). Cyclo-Oxygenase (COX) Inhibitors and Cardiovascular Risk: Are Non-Steroidal Anti-Inflammatory Drugs Really Anti-Inflammatory? Int J Mol Sci, 20.

Khan, Y. S., Gutierrez-de-Teran, H., \& Aqvist, J. (2018). Molecular Mechanisms in the Selectivity of Nonsteroidal Anti-Inflammatory Drugs. Biochemistry, 57, 1236-1248.

Kilbom, A., \& Wennmalm, A. (1976). Endogenous prostaglandins as local regulators of blood flow in man: effect of indomethacin on reactive and functional hyperaemia. J Physiol, 257, 109-121.

Kirkby, N. S., Chan, M. V., Zaiss, A. K., Garcia-Vaz, E., Jiao, J., Berglund, L. M., Verdu, E. F., AhmetajShala, B., Wallace, J. L., Herschman, H. R., Gomez, M. F., \& Mitchell, J. A. (2016). Systematic study of constitutive cyclooxygenase-2 expression: Role of NF-kappaB and NFAT transcriptional pathways. Proc Natl Acad Sci U S A, 113, 434-439.

Kirkby, N. S., Lundberg, M. H., Harrington, L. S., Leadbeater, P. D., Milne, G. L., Potter, C. M., AlYamani, M., Adeyemi, O., Warner, T. D., \& Mitchell, J. A. (2012). Cyclooxygenase-1, not cyclooxygenase-2, is responsible for physiological production of prostacyclin in the cardiovascular system. Proc Natl Acad Sci U S A, 109, 17597-17602.

Kirkby, N. S., Lundberg, M. H., Wright, W. R., Warner, T. D., Paul-Clark, M. J., \& Mitchell, J. A. (2014). COX-2 protects against atherosclerosis independently of local vascular prostacyclin: identification of COX-2 associated pathways implicate Rgl1 and lymphocyte networks. PLoS One, 9, e98165.

Kirkby, N. S., Raouf, J., Ahmetaj-Shala, B., Liu, B., Mazi, S. I., Edin, M. L., Chambers, M. G., Korotkova, M., Wang, X., Wahli, W., Zeldin, D. C., Nusing, R., Zhou, Y., Jakobsson, P. J., \& Mitchell, J. A. (2019). Mechanistic definition of the cardiovascular mPGES-1/COX-2/ADMA axis. Cardiovasc Res.

Kirkby, N. S., Reed, D. M., Edin, M. L., Rauzi, F., Mataragka, S., Vojnovic, I., Bishop-Bailey, D., Milne, G. L., Longhurst, H., Zeldin, D. C., Mitchell, J. A., \& Warner, T. D. (2015). Inherited human group IVA cytosolic phospholipase A2 deficiency abolishes platelet, endothelial, and leucocyte eicosanoid generation. FASEB J, 29, 4568-4578. 
Kirkby, N. S., Zaiss, A. K., Urquhart, P., Jiao, J., Austin, P. J., Al-Yamani, M., Lundberg, M. H., MacKenzie, L. S., Warner, T. D., Nicolaou, A., Herschman, H. R., \& Mitchell, J. A. (2013). LC$\mathrm{MS} / \mathrm{MS}$ confirms that COX-1 drives vascular prostacyclin whilst gene expression pattern reveals non-vascular sites of COX-2 expression. PLoS One, 8, e69524.

Kis, B., Snipes, J. A., \& Busija, D. W. (2005). Acetaminophen and the cyclooxygenase-3 puzzle: sorting out facts, fictions, and uncertainties. J Pharmacol Exp Ther, 315, 1-7.

Kis, B., Snipes, J. A., Gaspar, T., Lenzser, G., Tulbert, C. D., \& Busija, D. W. (2006). Cloning of cyclooxygenase-1b (putative COX-3) in mouse. Inflamm Res, 55, 274-278.

Knowles, R. B., \& Warner, T. D. (2019). Anti-platelet drugs and their necessary interaction with endothelial mediators and platelet cyclic nucleotides for therapeutic efficacy. Pharmacol Ther, 193, 83-90.

Kobzar, G., Mardla, V., Jarving, I., \& Samel, N. (2001). Comparison of anti-aggregatory effects of PGI2, PGI3 and iloprost on human and rabbit platelets. Cell Physiol Biochem, 11, 279-284.

Komhoff, M., Grone, H. J., Klein, T., Seyberth, H. W., \& Nusing, R. M. (1997). Localization of cyclooxygenase- 1 and -2 in adult and fetal human kidney: implication for renal function. $A m$ J Physiol, 272, F460-468.

Kondo, K., Okuno, T., Saruta, T., \& Kato, E. (1979). Effects of intracerebroventricular administration of prostaglandins 12, E2, F2 alpha and indomethacin on blood pressure in the rat. Prostaglandins, 17, 769-774.

Lee, C. H., Chawla, A., Urbiztondo, N., Liao, D., Boisvert, W. A., Evans, R. M., \& Curtiss, L. K. (2003). Transcriptional repression of atherogenic inflammation: modulation by PPARdelta. Science, 302, 453-457.

Levin, R. I., Weksler, B. B., \& Jaffe, E. A. (1982). The interaction of sodium nitroprusside with human endothelial cells and platelets: nitroprusside and prostacyclin synergistically inhibit platelet function. Circulation, 66, 1299-1307.

Li, S., Liu, B., Luo, W., Zhang, Y., Li, H., Huang, D., \& Zhou, Y. (2016). Role of cyclooxygenase-1 and -2 in endothelium-dependent contraction of atherosclerotic mouse abdominal aortas. Clin Exp Pharmacol Physiol, 43, 67-74.

Lidbury, P. S., Antunes, E., de Nucci, G., \& Vane, J. R. (1989). Interactions of iloprost and sodium nitroprusside on vascular smooth muscle and platelet aggregation. Br J Pharmacol, 98, 1275-1280.

Lin, H., Lin, T. N., Cheung, W. M., Nian, G. M., Tseng, P. H., Chen, S. F., Chen, J. J., Shyue, S. K., Liou, J. Y., Wu, C. W., \& Wu, K. K. (2002). Cyclooxygenase-1 and bicistronic cyclooxygenase$1 /$ prostacyclin synthase gene transfer protect against ischemic cerebral infarction. Circulation, 105, 1962-1969.

Liu, B., Luo, W., Zhang, Y., Li, H., Zhu, N., Huang, D., \& Zhou, Y. (2012). Role of cyclooxygenase-1mediated prostacyclin synthesis in endothelium-dependent vasoconstrictor activity of porcine interlobular renal arteries. Am J Physiol Renal Physiol, 302, F1133-1140.

Luo, W., Liu, B., \& Zhou, Y. (2016). The endothelial cyclooxygenase pathway: Insights from mouse arteries. Eur J Pharmacol, 780, 148-158.

Macdonald, P. S., Read, M. A., \& Dusting, G. J. (1988). Synergistic inhibition of platelet aggregation by endothelium-derived relaxing factor and prostacyclin. Thromb Res, 49, 437-449.

MacDonald, T. M., Hawkey, C. J., Ford, I., McMurray, J. J., Scheiman, J. M., Hallas, J., Findlay, E., Grobbee, D. E., Hobbs, F. D., Ralston, S. H., Reid, D. M., Walters, M. R., Webster, J., Ruschitzka, F., Ritchie, L. D., Perez-Gutthann, S., Connolly, E., Greenlaw, N., Wilson, A., Wei, L., \& Mackenzie, I. S. (2016). Randomized trial of switching from prescribed non-selective 
non-steroidal anti-inflammatory drugs to prescribed celecoxib: the Standard care vs. Celecoxib Outcome Trial (SCOT). Eur Heart J.

Marlicz, W., Loniewski, I., Grimes, D. S., \& Quigley, E. M. (2014). Nonsteroidal anti-inflammatory drugs, proton pump inhibitors, and gastrointestinal injury: contrasting interactions in the stomach and small intestine. Mayo Clin Proc, 89, 1699-1709.

Martel-Pelletier, J., Lajeunesse, D., Reboul, P., \& Pelletier, J. P. (2003). Therapeutic role of dual inhibitors of 5-LOX and COX, selective and non-selective non-steroidal anti-inflammatory drugs. Ann Rheum Dis, 62, 501-509.

McGettigan, P., \& Henry, D. (2011). Cardiovascular risk with non-steroidal anti-inflammatory drugs: systematic review of population-based controlled observational studies. PLoS Med, 8, e1001098.

McIntosh, G. H., McLennan, P. L., Lawson, C. A., Bulman, F. H., \& Charnock, J. S. (1985). The influence of dietary fats on plasma lipids, blood pressure and coagulation indices in the rat. Atherosclerosis, 55, 125-134.

Meade, E. A., Smith, W. L., \& DeWitt, D. L. (1993). Differential inhibition of prostaglandin endoperoxide synthase (cyclooxygenase) isozymes by aspirin and other non-steroidal antiinflammatory drugs. J Biol Chem, 268, 6610-6614.

Midgett, C., Stitham, J., Martin, K., \& Hwa, J. (2011). Prostacyclin receptor regulation--from transcription to trafficking. Curr Mol Med, 11, 517-528.

Mitchell, J. A., Ahmetaj-Shala, B., Kirkby, N. S., Wright, W. R., Mackenzie, L. S., Reed, D. M., \& Mohamed, N. (2014). Role of prostacyclin in pulmonary hypertension. Glob Cardiol Sci Pract, 2014, 382-393.

Mitchell, J. A., Akarasereenont, P., Thiemermann, C., Flower, R. J., \& Vane, J. R. (1993). Selectivity of nonsteroidal antiinflammatory drugs as inhibitors of constitutive and inducible cyclooxygenase. Proc Natl Acad Sci U S A, 90, 11693-11697.

Mitchell, J. A., \& Kirkby, N. S. (2019). Eicosanoids, prostacyclin and cyclooxygenase in the cardiovascular system. Br J Pharmacol, 176, 1038-1050.

Mitchell, J. A., Knowles, R. B., Kirkby, N. S., Reed, D. M., Edin, M. L., White, W. E., Chan, M. V., Longhurst, H., Yaqoob, M. M., Milne, G. L., Zeldin, D. C., \& Warner, T. D. (2018). Kidney Transplantation in a Patient Lacking Cytosolic Phospholipase A2 Proves Renal Origins of Urinary PGI-M and TX-M. Circ Res, 122, 555-559.

Mitchell, J. A., Shala, F., Elghazouli, Y., Warner, T. D., Gaston-Massuet, C., Crescente, M., Armstrong, P. C., Herschman, H. R., \& Kirkby, N. S. (2019). Cell-Specific Gene Deletion Reveals the Antithrombotic Function of COX1 and Explains the Vascular COX1/Prostacyclin Paradox. Circ Res, 125, 847-854.

Moncada, S., Korbut, R., Bunting, S., \& Vane, J. R. (1978). Prostacyclin is a circulating hormone. Nature, 273, 767-768.

Nagaya, N., Yokoyama, C., Kyotani, S., Shimonishi, M., Morishita, R., Uematsu, M., Nishikimi, T., Nakanishi, N., Ogihara, T., Yamagishi, M., Miyatake, K., Kaneda, Y., \& Tanabe, T. (2000). Gene transfer of human prostacyclin synthase ameliorates monocrotaline-induced pulmonary hypertension in rats. Circulation, 102, 2005-2010.

Nakayama, T. (2010). Genetic polymorphisms of prostacyclin synthase gene and cardiovascular disease. Int Angiol, 29, 33-42.

Nakayama, T., Soma, M., Rehemudula, D., Takahashi, Y., Tobe, H., Satoh, M., Uwabo, J., Kunimoto, M., \& Kanmatsuse, K. (2000). Association of 5' upstream promoter region of prostacyclin synthase gene variant with cerebral infarction. Am J Hypertens, 13, 1263-1267. 
Nakayama, T., Soma, M., Watanabe, Y., Hasimu, B., Sato, M., Aoi, N., Kosuge, K., Kanmatsuse, K., Kokubun, S., Marrow, J. D., \& Oates, J. A. (2002). Splicing mutation of the prostacyclin synthase gene in a family associated with hypertension. Biochem Biophys Res Commun, 297, 1135-1139.

Nelson, J. R., \& Raskin, S. (2019). The eicosapentaenoic acid:arachidonic acid ratio and its clinical utility in cardiovascular disease. Postgrad Med, 131, 268-277.

Newby, A. C., \& Baker, A. H. (1999). Targets for gene therapy of vein grafts. Curr Opin Cardiol, 14, 489-494.

Nieman, D. C., Henson, D. A., Dumke, C. L., Oley, K., McAnulty, S. R., Davis, J. M., Murphy, E. A., Utter, A. C., Lind, R. H., McAnulty, L. S., \& Morrow, J. D. (2006). Ibuprofen use, endotoxemia, inflammation, and plasma cytokines during ultramarathon competition. Brain Behav Immun, 20, 578-584.

Nissen, S. E., Yeomans, N. D., Solomon, D. H., Luscher, T. F., Libby, P., Husni, M. E., Graham, D. Y., Borer, J. S., Wisniewski, L. M., Wolski, K. E., Wang, Q., Menon, V., Ruschitzka, F., Gaffney, M., Beckerman, B., Berger, M. F., Bao, W., Lincoff, A. M., \& Investigators, P. T. (2016). Cardiovascular Safety of Celecoxib, Naproxen, or Ibuprofen for Arthritis. N Engl J Med, 375, 2519-2529.

Noon, J. P., Walker, B. R., Hand, M. F., \& Webb, D. J. (1998). Studies with iontophoretic administration of drugs to human dermal vessels in vivo: cholinergic vasodilatation is mediated by dilator prostanoids rather than nitric oxide. Br J Clin Pharmacol, 45, 545-550.

Okahara, K., Sun, B., \& Kambayashi, J. (1998). Upregulation of prostacyclin synthesis-related gene expression by shear stress in vascular endothelial cells. Arterioscler Thromb Vasc Biol, 18, 1922-1926.

Ozen, G., Gomez, I., Daci, A., Deschildre, C., Boubaya, L., Teskin, O., Uydes-Dogan, B. S., Jakobsson, P. J., Longrois, D., Topal, G., \& Norel, X. (2017). Inhibition of microsomal PGE synthase-1 reduces human vascular tone by increasing PGI2 : a safer alternative to COX-2 inhibition. $B r J$ Pharmacol, 174, 4087-4098.

Padol, I. T., \& Hunt, R. H. (2010). Association of myocardial infarctions with COX-2 inhibition may be related to immunomodulation towards a Th1 response resulting in atheromatous plaque instability: an evidence-based interpretation. Rheumatology (Oxford), 49, 837-843.

Palombo, J. D., DeMichele, S. J., Lydon, E. E., Gregory, T. J., Banks, P. L., Forse, R. A., \& Bistrian, B. R. (1996). Rapid modulation of lung and liver macrophage phospholipid fatty acids in endotoxemic rats by continuous enteral feeding with $\mathrm{n}-3$ and gamma-linolenic fatty acids. Am J Clin Nutr, 63, 208-219.

Parepally, J. M., Mandula, H., \& Smith, Q. R. (2006). Brain uptake of nonsteroidal anti-inflammatory drugs: ibuprofen, flurbiprofen, and indomethacin. Pharm Res, 23, 873-881.

Pifer, D. D., Cagen, L. M., \& Chesney, C. M. (1981). Stability of prostaglandin 12 in human blood. Prostaglandins, 21, 165-175.

Pirich, C., Efthimiou, Y., O'Grady, J., \& Sinzinger, H. (1997). Hyperalphalipoproteinemia and prostaglandin 12 stability. Thromb Res, 88, 41-49.

Pirlamarla, P., \& Bond, R. M. (2016). FDA labeling of NSAIDs: Review of nonsteroidal antiinflammatory drugs in cardiovascular disease. Trends Cardiovasc Med, 26, 675-680.

Qian, H., Luo, N., \& Chi, Y. (2012). Aging-shifted prostaglandin profile in endothelium as a factor in cardiovascular disorders. J Aging Res, 2012, 121390.

Radi, Z. A., \& Khan, K. N. (2019). Cardio-renal safety of non-steroidal anti-inflammatory drugs. J Toxicol Sci, 44, 373-391. 
Radomski, M. W., Palmer, R. M., \& Moncada, S. (1987). The anti-aggregating properties of vascular endothelium: interactions between prostacyclin and nitric oxide. Br J Pharmacol, 92, 639646.

Ricciotti, E., Castro, C., Tang, S. Y., Briggs, W. T. E., West, J. A., Malik, D., Rhoades, S. D., Meng, H., Li, X., Lahens, N. F., Sparks, J. A., Karlson, E. W., Weljie, A. M., Griffin, J. L., \& FitzGerald, G. A. (2018). Cyclooxygenase-2, Asymmetric Dimethylarginine, and the Cardiovascular Hazard From Nonsteroidal Anti-Inflammatory Drugs. Circulation, 138, 2367-2378.

Rocca, B., Maggiano, N., Habib, A., Petrucci, G., Gessi, M., Fattorossi, A., Lauriola, L., Landolfi, R., \& Ranelletti, F. O. (2002). Distinct expression of cyclooxygenase- 1 and -2 in the human thymus. Eur J Immunol, 32, 1482-1492.

Safiah Mokhtar, S., P, M. V., S, W. S. L., Imran Yusof, M., Wan Sulaiman, W. A., Zaharil Mat Saad, A., Suppian, R., \& Ghulam Rasool, A. H. (2013). Reduced expression of prostacyclin synthase and nitric oxide synthase in subcutaneous arteries of type 2 diabetic patients. Tohoku J Exp Med, 231, 217-222.

Schlesinger, S., Sonntag, S. R., Lieb, W., \& Maas, R. (2016). Asymmetric and Symmetric Dimethylarginine as Risk Markers for Total Mortality and Cardiovascular Outcomes: A Systematic Review and Meta-Analysis of Prospective Studies. PLoS One, 11, e0165811.

Senol, S., \& Senol, A. (2017). Investigation of Asymmetric and Symmetric Dimethylarginine Levels after Iloprost Treatment in Patients with Buerger's Disease. Eur J Vasc Endovasc Surg, 53, 439-442.

Shahin, N. N., Abdelkader, N. F., \& Safar, M. M. (2018). A Novel Role of Irbesartan in Gastroprotection against Indomethacin-Induced Gastric Injury in Rats: Targeting DDAH/ADMA and EGFR/ERK Signaling. Sci Rep, 8, 4280.

Shimamura, M., Nakagami, H., Taniyama, Y., \& Morishita, R. (2014). Gene therapy for peripheral arterial disease. Expert Opin Biol Ther, 14, 1175-1184.

Sigthorsson, G., Tibble, J., Hayllar, J., Menzies, I., Macpherson, A., Moots, R., Scott, D., Gumpel, M. J., \& Bjarnason, I. (1998). Intestinal permeability and inflammation in patients on NSAIDs. Gut, 43, 506-511.

Sinzinger, H., Fitscha, P., \& Tiso, B. (1990). Decreased prostaglandin-12 stability in acute myocardial infarction. Thromb Res, 57, 677-684.

Sinzinger, H., Zidek, T., Fitscha, P., O'Grady, J., Wagner, O., \& Kaliman, J. (1987). Prostaglandin 12 reduces activation of human arterial smooth muscle cells in-vivo. Prostaglandins, 33, 915918.

Siren, A. L. (1982a). Central cardiovascular and thermal effects of prostaglandin D2 in rats. Prostaglandins Leukot Med, 8, 349-359.

Siren, A. L. (1982b). Differences in the central actions of arachidonic acid and prostaglandin F2 alpha between spontaneously hypertensive and normotensive rats. Life Sci, 30, 503-513.

Sitar, M. E. (2016). Asymmetric Dimethylarginine and Its Relation As a Biomarker in Nephrologic Diseases. Biomark Insights, 11, 131-137.

Slavik, R. S., \& Rhoney, D. H. (1999). Indomethacin: a review of its cerebral blood flow effects and potential use for controlling intracranial pressure in traumatic brain injury patients. Neurol Res, 21, 491-499.

Snipes, J. A., Kis, B., Shelness, G. S., Hewett, J. A., \& Busija, D. W. (2005). Cloning and characterization of cyclooxygenase-1b (putative cyclooxygenase-3) in rat. J Pharmacol Exp Ther, 313, 668-676. 
Solmaz, D., Sari, I., Can, G., Akar, S., Ceylan, I., Secil, M., \& Akkoc, N. (2012). The effect of nonsteroidal anti-inflammatory drugs on the endothelial function of patients with osteoarthritis in short term. Int J Rheum Dis, 15, 207-211.

Stein, R. W., Papp, A. C., Weiner, W. J., \& Wu, K. K. (1985). Reduction of serum prostacyclin stability in ischemic stroke. Stroke, 16, 16-18.

Stokes, A., Berry, K. M., Hempstead, K., Lundberg, D. J., \& Neogi, T. (2019). Trends in Prescription Analgesic Use Among Adults With Musculoskeletal Conditions in the United States, 19992016. JAMA Netw Open, 2, e1917228.

Tahsili-Fahadan, P., \& Geocadin, R. G. (2017). Heart-Brain Axis: Effects of Neurologic Injury on Cardiovascular Function. Circ Res, 120, 559-572.

Tallima, H., \& El Ridi, R. (2018). Arachidonic acid: Physiological roles and potential health benefits A review. J Adv Res, 11, 33-41.

Tang, S. Y., Monslow, J., Todd, L., Lawson, J., Pure, E., \& FitzGerald, G. A. (2014). Cyclooxygenase-2 in endothelial and vascular smooth muscle cells restrains atherogenesis in hyperlipidemic mice. Circulation, 129, 1761-1769.

Trepanier, C. H., \& Milgram, N. W. (2010). Neuroinflammation in Alzheimer's disease: are NSAIDs and selective COX-2 inhibitors the next line of therapy? J Alzheimers Dis, 21, 1089-1099.

Tse, K., Tse, H., Sidney, J., Sette, A., \& Ley, K. (2013). T cells in atherosclerosis. International immunology, 25, 615-622.

Tuder, R. M., Cool, C. D., Geraci, M. W., Wang, J., Abman, S. H., Wright, L., Badesch, D., \& Voelkel, N. F. (1999). Prostacyclin synthase expression is decreased in lungs from patients with severe pulmonary hypertension. Am J Respir Crit Care Med, 159, 1925-1932.

Tugendreich, S., Pearson, C. I., Sagartz, J., Jarnagin, K., \& Kolaja, K. (2006). NSAID-induced acute phase response is due to increased intestinal permeability and characterized by early and consistent alterations in hepatic gene expression. Toxicologic pathology, 34, 168-179.

Ungprasert, P., Srivali, N., \& Kittanamongkolchai, W. (2015). Non-steroidal anti-inflammatory drugs and risk of heart failure exacerbation: A systematic review and meta-analysis. Eur J Intern Med, 26, 685-690.

Vane, J. R., Mitchell, J. A., Appleton, I., Tomlinson, A., Bishop-Bailey, D., Croxtall, J., \& Willoughby, D. A. (1994). Inducible isoforms of cyclooxygenase and nitric-oxide synthase in inflammation. Proc Natl Acad Sci U S A, 91, 2046-2050.

Vardeh, D., Wang, D., Costigan, M., Lazarus, M., Saper, C. B., Woolf, C. J., Fitzgerald, G. A., \& Samad, T. A. (2009). COX2 in CNS neural cells mediates mechanical inflammatory pain hypersensitivity in mice. J Clin Invest, 119, 287-294.

Verhoeven, F., Totoson, P., Marie, C., Prigent-Tessier, A., Wendling, D., Tournier-Nappey, M., Prati, C., \& Demougeot, C. (2017). Diclofenac but not celecoxib improves endothelial function in rheumatoid arthritis: A study in adjuvant-induced arthritis. Atherosclerosis, 266, 136-144.

Verma, S., Raj, S. R., Shewchuk, L., Mather, K. J., \& Anderson, T. J. (2001). Cyclooxygenase-2 blockade does not impair endothelial vasodilator function in healthy volunteers: randomized evaluation of rofecoxib versus naproxen on endothelium-dependent vasodilatation. Circulation, 104, 2879-2882.

Wada, M., DeLong, C. J., Hong, Y. H., Rieke, C. J., Song, I., Sidhu, R. S., Yuan, C., Warnock, M., Schmaier, A. H., Yokoyama, C., Smyth, E. M., Wilson, S. J., FitzGerald, G. A., Garavito, R. M., Sui de, X., Regan, J. W., \& Smith, W. L. (2007). Enzymes and receptors of prostaglandin pathways with arachidonic acid-derived versus eicosapentaenoic acid-derived substrates and products. J Biol Chem, 282, 22254-22266. 
Walker, C., \& Biasucci, L. M. (2018). Cardiovascular safety of non-steroidal anti-inflammatory drugs revisited. Postgrad Med, 130, 55-71.

Wallace, J. L., McKnight, W., Reuter, B. K., \& Vergnolle, N. (2000). NSAID-induced gastric damage in rats: requirement for inhibition of both cyclooxygenase 1 and 2. Gastroenterology, 119, 706714.

Wang, L., Zhou, Y., Peng, J., Zhang, Z., Jiang, D. J., \& Li, Y. J. (2008). Role of endogenous nitric oxide synthase inhibitor in gastric mucosal injury. Can J Physiol Pharmacol, 86, 97-104.

Wang, M., Ihida-Stansbury, K., Kothapalli, D., Tamby, M. C., Yu, Z., Chen, L., Grant, G., Cheng, Y., Lawson, J. A., Assoian, R. K., Jones, P. L., \& Fitzgerald, G. A. (2011). Microsomal prostaglandin e2 synthase-1 modulates the response to vascular injury. Circulation, 123, 631-639.

Wang, M., Lee, E., Song, W., Ricciotti, E., Rader, D. J., Lawson, J. A., Pure, E., \& FitzGerald, G. A. (2008). Microsomal prostaglandin E synthase-1 deletion suppresses oxidative stress and angiotensin II-induced abdominal aortic aneurysm formation. Circulation, 117, 1302-1309.

Wang, M., Zukas, A. M., Hui, Y., Ricciotti, E., Pure, E., \& FitzGerald, G. A. (2006). Deletion of microsomal prostaglandin $\mathrm{E}$ synthase-1 augments prostacyclin and retards atherogenesis. Proc Natl Acad Sci U S A, 103, 14507-14512.

Warner, T. D., Giuliano, F., Vojnovic, I., Bukasa, A., Mitchell, J. A., \& Vane, J. R. (1999). Nonsteroid drug selectivities for cyclo-oxygenase-1 rather than cyclo-oxygenase-2 are associated with human gastrointestinal toxicity: a full in vitro analysis. Proc Natl Acad Sci U S A, 96, 75637568.

White, W. B. (2007). Cardiovascular effects of the cyclooxygenase inhibitors. Hypertension, 49, 408418.

Widlansky, M. E., Price, D. T., Gokce, N., Eberhardt, R. T., Duffy, S. J., Holbrook, M., Maxwell, C., Palmisano, J., Keaney, J. F., Jr., Morrow, J. D., \& Vita, J. A. (2003). Short- and long-term COX2 inhibition reverses endothelial dysfunction in patients with hypertension. Hypertension, 42, 310-315.

Wiedermann, C. J., Kiechl, S., Dunzendorfer, S., Schratzberger, P., Egger, G., Oberhollenzer, F., \& Willeit, J. (1999). Association of endotoxemia with carotid atherosclerosis and cardiovascular disease: prospective results from the Bruneck Study. J Am Coll Cardiol, 34, 1975-1981.

Wilson, J. R., \& Kapoor, S. C. (1993). Contribution of prostaglandins to exercise-induced vasodilation in humans. Am J Physiol, 265, H171-175.

Wu, K. K., Hall, E. R., Rossi, E. C., \& Papp, A. C. (1985). Serum prostacyclin binding defects in thrombotic thrombocytopenic purpura. J Clin Invest, 75, 168-174.

Wyss, J. M., \& Carlson, S. H. (1999). The role of the central nervous system in hypertension. Curr Hypertens Rep, 1, 246-253.

Yu, Y., Ricciotti, E., Grosser, T., \& Fitzgerald, G. A. (2009). The translational therapeutics of prostaglandin inhibition in atherothrombosis. J Thromb Haemost, 7 Suppl 1, 222-226.

Yu, Y., Ricciotti, E., Scalia, R., Tang, S. Y., Grant, G., Yu, Z., Landesberg, G., Crichton, I., Wu, W., Pure, E., Funk, C. D., \& FitzGerald, G. A. (2012). Vascular COX-2 modulates blood pressure and thrombosis in mice. Sci Transl Med, 4, 132ra154.

Yui, Y., Aoyama, T., Morishita, H., Takahashi, M., Takatsu, Y., \& Kawai, C. (1988). Serum prostacyclin stabilizing factor is identical to apolipoprotein A-I (Apo A-I). A novel function of Apo A-I. J Clin Invest, 82, 803-807. 
Zhang, M. Z., Yao, B., Wang, Y., Yang, S., Wang, S., Fan, X., \& Harris, R. C. (2015). Inhibition of cyclooxygenase-2 in hematopoietic cells results in salt-sensitive hypertension. J Clin Invest, $125,4281-4294$.

Zhang, Z. H., Wei, S. G., Francis, J., \& Felder, R. B. (2003). Cardiovascular and renal sympathetic activation by blood-borne TNF-alpha in rat: the role of central prostaglandins. Am J Physiol Regul Integr Comp Physiol, 284, R916-927.

Zidar, N., Odar, K., Glavac, D., Jerse, M., Zupanc, T., \& Stajer, D. (2009). Cyclooxygenase in normal human tissues--is COX-1 really a constitutive isoform, and COX-2 an inducible isoform? J Cell Mol Med, 13, 3753-3763. 